\section{SPAL 30.1 $(2021)$}

\section{$165-195$}

ISSN: $1133-4525$

ISSN-e: 2255-3924

\section{FECHA RECEPCIÓN}

$8 / 6 / 20$

FECHA ACEPTACIÓN

$25 / 11 / 20$

\title{
Evidencias arqueobotánicas para una historia del consumo y producción de vino en el Noroeste ibérico
}

\author{
ARCHAEOBOTANICAL EVIDENCE FOR A HISTORY OF WINE CONSUMPTION AND PRODUCTION IN \\ NORTHWESTERN IBERIA
}

\section{Andrés Teira Brión}

Departamento de Historia, Arte e Xeografía. Universidade de Vigo Edificio de Facultades. As Lagoas, s/n. 32004 Ourense, España andresmanuel.teira@uvigo.es (1) 0000-0001-8997-1425 P R-5865-2017/ (Responsable de correspondencia)

\section{Josefa Rey Castiñeira}

Departamento de Historia. Universidade de Santiago de Compostela Praza da Universidade 1, 15782 Santiago de Compostela, España josefa.rey@usc.es (1) 0000-0003-0102-0743 P ABD-5444-2020/

Resumen Los datos arqueobotánicos publicados en los últimos años en el noroeste de la península ibérica nos permiten trazar una evolución del cultivo de la vid con unas pautas cronológicas y unas características internas singulares. Los análisis polínicos, carpológicos y antracológicos han identificado la presencia de Vitis vinifera subsp. sylvestris en el medio natural y su aprovechamiento por las comunidades protohistóricas. En época romana, los conjuntos de algunos yacimientos sugieren el cultivo simultáneo de la vid doméstica -Vitis vinifera subsp. vinifera- y la silvestre. Además, destaca la aparición de los primeros asentamientos especializados en la producción de vino en el sur de la región. Esto indica cambios en la gestión de la vid. El viñedo se vincularía a establecimientos agropecuarios, propiedad de familias con un estatus social alto, situados en áreas rurales o próximos a núcleos urbanos. Estos grandes propietarios probablemente continuarían controlando la comercialización del excedente de vino en la Alta Edad Media.

Palabras clave Vid silvestre, domesticación, viticultura, arqueometría, diacronía Prehistoria-Edad Media

Abstract Recent archaeobotanical data published in the northwest of the Iberian peninsula make it possible to trace the evolution of vine cultivation with distinctive chronological patterns and internal characteristics. Pollen, carpological and charcoal analyses have identified the presence of Vitis vinifera subsp. sylvestris in the natural environment and its use by protohistoric communities. In the Roman period, the assemblages of some sites suggest the simultaneous cultivation of domestic vines -Vitis vinifera subsp. vinifera- and wild ones. In addition, the first settlements specializing in wine production appeared in the south of the region. These indicate changes in the management of the vine. Vineyard would be linked to agricultural establishments owned by families with a high social status located in rural areas or near urban settlements. These large owners would probably continue to control the commercialisation of wine surplus in the Early Middle Ages. Keywords Wild grape, domestication, viticulture, archaeometry, diachrony Prehistory-Middle Ages

Teira Brión, A. y Rey Castiñeira, J. (2021): “Evidencias arqueobotánicas para una historia del consumo y producción de vino en el Noroeste ibérico", Spal, 30.1, pp. 165 - 195. https://dx.doi.org/10.12795/spal.2021.i30.06 
SPAL 30.1

(2021)

\section{$165-195$}

ISSN: 1133-4525 ISSN-e: 2255-3924

\section{INTRODUCCIÓN}

La vid -Vitis vinifera L.- ha tenido un papel relevante en la economía y cultura de muchas comunidades desde la Protohistoria hasta nuestros días. El consumo de sus frutos y productos derivados (cf. Brun, 2011) se documenta abundantemente en el ámbito mediterráneo, biocenosis natural de esta especie (Zohary et al., 2012), y, al tiempo que comienza a cultivarse, se diversifica y expande a regiones de todo el mundo. Pero es en el consumo de vino, tomando parte en actos en comunidad o en entornos domésticos, donde más frecuentemente se expresa su dimensión social. El interés por su bebida ha permitido preservar una cantidad ingente y heterogénea de fuentes de información: registros arqueobotánicos, estructuras y objetos arqueológicos, textos documentales y representaciones iconográficas, entre otras; evidencias que abordan la reconstrucción de comportamientos individuales y sociales y sus codificaciones a lo largo del tiempo (Rodrigo-Estevan, 2016). Tales comportamientos señalan tendencias de producción y consumo susceptibles de analizarse interdisciplinar y multiescalarmente. Sin embargo, y a pesar de su potencialidad, el vino ha sido tratado de manera desigual en la literatura científica de la península ibérica. Así, su estudio se ha apoyado frecuentemente en los documentos escritos y en dos tipos de hallazgo arqueológico: las ánforas, como contenedores de productos derivados de la vid, y las estructuras de prensado de uva. Dentro de estos trabajos el Noroeste se ha situado al margen, debido a un desarrollo tardío de la investigación y al ser un centro tradicionalmente considerado receptor, no productor, dentro de las rutas comerciales entre el Atlántico y el Mediterráneo. En este sentido, la atención prestada a las evidencias vitivinícolas, o incluso a los contextos de consumo de vino, es escasa en comparación con otros territorios peninsulares ibéricos, tal y como refleja la casi ausencia de referencias en las monografías sobre el tema (cf. Francia Verde, 2015; Noguera Celdrán y Antolinos Marín, 2011-2012; Peña Cervantes, 2010).

Las investigaciones de la última década han propiciado un notable avance en la caracterización del cultivo y producción de la vid en el Noroeste peninsular ibérico. Resaltan trabajos que aportan un mejor conocimiento de las estructuras de transformación de uva (Almeida, 2011-2012; Rodríguez Muñiz et al., 2016) y los que surgen de la reciente vitalidad de la arqueobotánica. Disciplinas como la carpología (p.ej.: Teira Brión, 2019; Tereso, 2012) y la antracología (p.ej.: Vaz et al., 2016; Vaz et al., 2017) están visibilizando la identificación de evidencias vegetales y determinando su representatividad en los yacimientos arqueológicos. Los análisis polínicos están dibujando el mapa de la dispersión de la vid silvestre en las formaciones vegetales del medio natural. Al mismo tiempo se están dando pasos adelante en nuevas técnicas aplicadas. Los estudios morfométricos en semillas permiten la clasificación más precisa de variedades y de grupos tipo (p.ej. Boso et al., 2020; Bouby et al., 2013; Pagnoux et al., 2015; Terral et al., 2010; Ucchesu et al., 2016). De igual manera, la secuenciación del polimorfismo del ADN ha promovido avances significativos en el estudio de los genes relacionados con los rasgos del síndrome de domesticación, de selección entre especies u otros aspectos de interés agrícola (Bacilieri et al., 2017). Incluso es posible generar supuestos sobre orígenes geográficos de la vid a través de la diversidad morfológica y el parentesco determinado por enfoques genéticos (Terral et al., 2010). Y, finalmente, la aplicación de análisis de contenidos está mostrando grandes posibilidades en la definición de formas de consumo de los alimentos en las sociedades del pasado (Pecci et al., 2017). Estas aproximaciones están visibilizando contextos de uso, transformación y descarte y abordando preguntas sobre sus pautas sociales y económicas. 
SPAL 30.1

(2021)

\section{$165-195$}

ISSN: 1133-4525 ISSN-e: 2255-3924

\subsection{Primeras evidencias del cultivo de Vitis vinifera $L$.}

Los inicios del cultivo de la vid en la península ibérica están ligados al establecimiento de emporia comerciales fenicios y griegos (Buxó, 2008; López et al., 2014; Pérez Jordá, 2015; Pérez-Jordà et al., 2021). Las semillas más antiguas de la variedad doméstica se han localizado en la ría de Huelva, fechadas en 891-787 cal BC (Pérez-Jordá et al., 2017); un área en torno a la que también se encuentran los primeros ejemplos de sistemas de plantación de viñedo (Echevarría Sánchez y Vera Rodríguez, 2015). Su introducción estaría relacionada con la llegada de un nuevo modelo agrícola de tradición mediterránea basado en los frutales (Pérez-Jordà et al., 2021). Los hallazgos de granos de uva en contextos de la primera mitad del I milenio a.n.e. en yacimientos del noreste -Font de la Canya (López et al., 2014)-, del Ebro -Cabezo de la Cruz (Pérez-Jordà et al., 2021)-, de la costa levantina -Alt de Benimaquía (Pérez-Jordà et al., 2021) - o del sur -Huelva y Gadir (Pérez-Jordà et al., 2021) - constatan la pronta asimilación de la vid en la cultura ibérica. Lagares, unidades de producción de vino y evidencias arqueobotánicas habrían sido varios de sus elementos identificativos (cf. Buxó, 2008).

La interculturalidad entre asentamientos coloniales e íberos habría supuesto el conocimiento de los sistemas agrícolas basados en la arboricultura y del consumo de productos de la vid en la Edad del Hierro. Hasta el siglo III a.n.e. la producción de vino se habría incorporado a la región mediterránea, al litoral atlántico del área del Estrecho y áreas adyacentes como el valle del Ebro y las cuencas del Guadalquivir y Guadiana (cf. Alonso Martínez, 2000; Burillo Mozota, 2010; Buxó, 2008; Pérez Jordá, 2015; Pérez-Jordà et al., 2021). Es a partir de época romana cuando se produce una expansión en la Península y en toda Europa Occidental (Brun, 2004; Peña-Chocarro et al., 2019), llegando a cultivarse en zonas tan al norte como Gran Bretaña (Brown et al., 2001). La economía del vino para exportación habría originado nuevas regiones productoras a partir del I a.n.e. (cf. Martín i Oliveras et al., 2017) y, al mismo tiempo, habría extendido ritualidades y gestualidades en el consumo. Así, es durante la Antigüedad cuando la frecuencia de las semillas Vitis en zonas del Norte, Noroeste y centro peninsular ibérico (cf. Peña-Chocarro et al., 2019; Peña-Chocarro y Zapata, 2005; Teira Brión, 2019) posibilitaría hablar de cultivo en toda Hispania, si bien con diferencias en su implantación, o de áreas de consumo.

\subsection{La vid en el Noroeste peninsular ibérico: un breve estado de la cuestión}

Las hipótesis sobre la distribución, el valor social y el rol de la vid desde la Protohistoria hasta la Edad Media en el Noroeste ibérico se han basado fundamentalmente en fuentes escritas y materiales arqueológicos: sobre citas frecuentes a Estrabón (Strab. 3.3.7), quien menciona el consumo esporádico de vino por las poblaciones de montañeses (Estrabón, 1992), aun refiriéndose a comunidades de un territorio impreciso que comprende la franja norte del Atlántico hasta los Pirineos; o sobre la llegada de vino de importación, deducido por el incremento de ánforas vinarias de otras regiones de la Península (Naveiro López, 1991), si bien, como se ha advertido, conocer su procedencia no implica necesariamente reconocer el producto transportado (cf. Bernal Casasola, 2015). Técnicas que posibilitan determinar los contenidos en las cerámicas, como la combinación de la cromatografía de gases y la espectrometría de masas, tienen una implantación aún incipiente y los resultados hasta la fecha no alcanzan a establecer un conocimiento preciso de las preferencias comerciales que llegan hasta estas costas. Sin embargo, sí han proporcionado evidencias que nos hablan de un mercado para los 
SPAL 30.1

(2021)

\section{$165-195$}

ISSN: 1133-4525

ISSN-e: 2255-3924 vinos del área del Estrecho (cf. Oliveira et al., 2015). En el ámbito de la iconografía se han señalado representaciones de racimos y hojas de vid (Suárez Piñeiro, 2005) e iconografías vinculadas a cultos dionisíacos (Díez Platas, 2003). Por último, las prensas de uva han encontrado recientemente un nicho entre las investigaciones de los contextos de producción de vino (p.ej. Almeida, 2011-2012; Brun, 2004; Rodríguez Muñiz et al., 2016).

Si bien el consumo de vino procedente de transacciones comerciales no parece albergar dudas, una de las principales cuestiones a resolver es establecer cuándo y a qué escala se habría gestionado la vid y/o cultivado al norte del río Duero. Constatamos restos carpológicos en algunos asentamientos prerromanos (cf. Tereso, 2012), sin embargo, su estudio no ha permitido desvelar si estamos ante semillas recolectadas de la variedad silvestre o ante la especie doméstica. Los problemas en la identificación de las semillas y de los contextos productivos en el I milenio a.n.e. han derivado en propuestas en torno a un posible límite climático durante la Antigüedad (Ramil Rego et al., 2012), con un cultivo destinado a la producción vitivinícola solo en el tramo final del valle del Duero (Tereso et al., 2013a). Y, además, ha provocado que el centro de las hipótesis se haya establecido desde la perspectiva de la documentación escrita, negando su cultivo en Galicia hasta la Edad Media según algunos autores (Ramil Rego et al., 2012). Este es un período para el que tenemos abundantes fuentes que transmiten la existencia de viñas en los huertos, granjas dependientes de monasterios o la plantación de viñedos en nuevas tierras para el pago de los foros, principalmente documentación eclesiástica bajomedieval (cf. López Sabatel, 2007; Portela Silva, 1976; Portela Silva y Pallares Méndez, 1998).

Uno de los temas más enriquecedores en torno a la vid se está generando en la identificación de eventos de domesticación y expansión de las variedades cultivadas en Europa (Riaz et al., 2018). Si bien la Vitis doméstica más antigua procede de Oriente Próximo (Bacilieri et al., 2017), asociada a los inicios de la arboricultura (Fuller y Stevens, 2019), los análisis morfométricos y de ADN sustentan procesos de domesticación locales en el occidente europeo a partir del cultivo de variedades silvestres e, incluso, procesos de hibridación entre las variedades domesticadas en Próximo Oriente y las silvestres (Arroyo-García et al., 2006; Bouby et al., 2013; Limier et al., 2018; Riaz et al., 2018; Wales et al., 2016). Los recientes trabajos morfométricos sobre semillas de vid de las salinas romanas de O Areal -Vigo- parecen indicar una gestión cruzada entre variedades silvestres y domésticas, lo que supondría, al menos hipotéticamente, una domesticación local (Boso et al., 2020). Los análisis de ADN sobre poblaciones actuales del centro de Portugal apuntan a que algunas de las variedades cultivadas procederían o se habrian mezclado con poblaciones silvestres en el pasado, lo que supondría eventos secundarios de domesticación o bien una introgresión posterior de $V$. sylvestris en las cepas de V. sativa (Cunha et al., 2020). Por lo tanto, ese escenario en que ambas variedades se hibridaron en el Noroeste es una de las cuestiones que nuevas aportaciones deberán establecer y que debiera confirmarse por la genética de evidencias arqueobotánicas.

Hoy en día, el cultivo de la vid en el Noroeste se asocia mayormente a zonas de monocultivo y a una amplia extensión de altitudes inferiores a los 800 metros, ligada tradicionalmente a una explotación familiar cada vez más en regresión y en substitución por la producción para bodegas. Las áreas de mayor extensión del viñedo dentro del ámbito bioclimático mediterráneo (SE y S) se expanden por la cuenca del río Douro/Duero y sus afluentes. En el área bioclimática atlántica -O y N- se distribuye por valles fluviales -cuencas de los ríos Lima/Limia, Miño/Minho, Sil, Lérez y Ulla- y áreas costeras atlánticas de las Rías Baixas. La producción en los demás territorios es sensiblemente inferior. En el litoral norte y cantábrico su desarrollo está limitado a algunos pequeños valles costeros -Betanzos, viveiro- y a 
SPAL 30.1

(2021)

$165-195$

ISSN: $1133-4525$ ISSN-e: 2255-3924 fondos de valle de baja altitud con un microclima que facilita su cultivo, como son las cuencas del Navia o el Narcea en Asturias. Fuera de estas zonas se presenta de manera mucho más dispersa para autoconsumo o como planta ornamental para dar sombra.

\section{OBJETIVOS Y MATERIALES}

En los últimos años, la intensa publicación de resultados arqueobotánicos ha supuesto un substancial incremento de la información disponible de las variedades conocidas de Vitis vinifera L. en el Noroeste (p.ej. Boso et al., 2020; Peña-Chocarro et al., 2019; Teira Brión, 2019; Tereso et al., 2016; Tereso et al. 2013a). Este escenario de múltiples líneas de investigación es propicio para el estudio de los procesos agrícolas y la gestión de la vid en el pasado. Su sistematización nos brinda la posibilidad de teorizar cuándo y cómo se inició el cultivo de la vid y el consumo de vino, y nos permite explorar hábitos sociales y su importancia económica. Este texto tiene como objetivo rastrear las escalas de producción, consumo y descarte de la vid a través de los datos arqueobotánicos disponibles en yacimientos arqueológicos desde la Protohistoria hasta la Alta Edad Media -fig. 1, tab. 1, tab. 2. Esta información nos permitirá observar tendencias cronológicas y comportamientos espaciales en la gestión y aprovechamiento de la vid silvestre o en el cultivo de viñedo en el Noroeste ibérico. Para ello, se parte de una compilación de referencias publicadas e investigaciones inéditas que nos acercan a las evidencias conservadas de la planta de la vid, es decir, de análisis carpológicos, antracológicos, polínicos y de contenidos vinculados a la elaboración y al consumo de sus productos.

\section{RESULTADOS}

Los análisis polínicos confirman el crecimiento de la vid silvestre en el área septentrional del Noroeste durante el Holoceno (tab. 1). Desde el IV milenio a.n.e. se documenta polen y madera de Vitis en varios depósitos de formación natural. En la costa cantábrica se ha identificado en registros de Villaviciosa -Asturias- (García-Amorena et al., 2008; Iriarte Chiapusso y Hernández Beloqui, 2009; Sánchez-Goñi, 1996). Columnas hechas sobre turberas de cobertor en la Serra do Xistral -norte de la provincia de Lugo- han recuperado polen en varias muestras de As Borralleiras da Cal Grande y de Pena da Cadela (Mighall et al., 2006). En la laguna de Braña Rubia -Coristanco, A Coruña- aparece en los depósitos basales, estimándose finales del I milenio a.n.e. para el comienzo de su sedimentación (Tornqvist et al., 1989).

Las evidencias de Vitis sp son escasas antes del I milenio a.n.e. Aun así se han recuperado semillas en yacimientos del norte de Portugal: en niveles del Calcolítico en Buraco da Pala (Ramil Rego y Aira Rodríguez, 1993) y junto a pedicelos de uva en Terraço das Laranjeiras (Jesus et al., 2020). En el dolmen neolítico de Mamoa da Arcã (Figueiral y Sanches, 1998-1999), en los niveles calcolíticos del Crasto de Palheiros (Figueiral et al., 2017) -aunque la datación de algunas muestras es controvertida- y también en el yacimiento de fosas del Bronce Medio de O Freixo (Martín Seijo, comentario personal) se documenta madera carbonizada de Vitis vinifera.

En el I milenio hasta el inicio de la conquista romana (138-19 a.n.e) los yacimientos con restos carpológicos y antracológicos son varios. Una única semilla de Vitis sp en São Julião (Aira Rodríguez y Ramil Rego, 1995) y Quinta de Crestelos (Vaz et al., 2017), 21 pepitas en Crastoeiro (Seabra et al., 2018a, b) y un total de 14 en niveles prerromanos del castro de Briteiros 


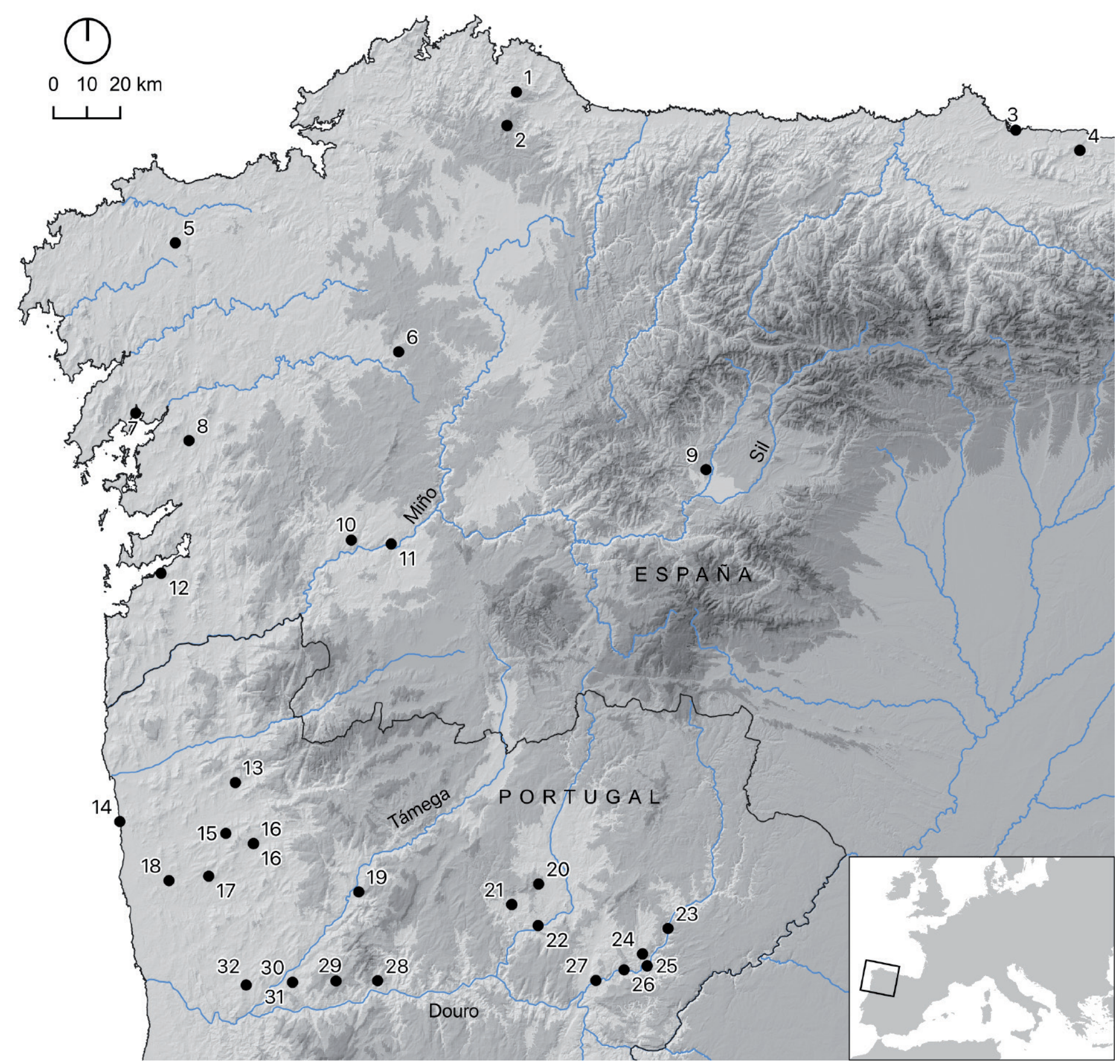

Figura 1. Yacimientos con evidencias arqueobotánicas de vid: 1) As Borralleiras da Cal Grande; 2) Pena da Cadela, 3) Tabacalera de Gijón, 4) Villaviciosa, 5) Braña Rubia, 6) A Fontela, 7) O Neixón Grande, 8) Rúa Ferreiría, 9) Castro Ventosa, 10) San Cibrao de Las, 11) Reza Vella, 12) O Areal, 13) São Julião, 14) Praia do Ribeiro de Peralta, 15) Bracara Augusta -Oficina de S. José-, 16) Briteiros, 17) Cruito, 18) Castro de Penices, 19) Crastoeiro, 20) Buraco da Pala, 21) Crasto de Palheiros, 22) Mamoa da Arcã, 23) Foz da Ribeira do Poio, 24) Chã, 25) Quinta de Crestelos, 26) Castelinho, 27) Terraço das Laranjeiras, 28) Cidadelhe, 29) Castelo de Matos, 30) O Freixo, 31) Tongobriga 32) Monte Mozinho.

(Tereso, 2012). Además se identifican semillas y pedicelos en el Crasto de Palheiros (Leite et al., 2018). Todos estos yacimientos están situados en el sur de la región. La única localización en el área septentrional procede de una columna polínica del yacimiento de A Fontela, cuya muestra se ha datado en la Primera Edad del Hierro -795-542 cal BC- (Teira Brión, 2019).

Los contextos fechados en la etapa de transición al período romano, siglos II/I a.n.e., vuelven a localizarse en el área meridional. Todos los restos arqueobotánicos proceden de modelos de poblamiento propios de la Edad del Hierro (castros) en un momento de asimilación a las estructuras sociopolíticas romanas. Se trata de los castros de Chã (Vaz et al., 2016b), Briteiros (Tereso, 2012) y de varios yacimientos de la cuenca del río Sabor, afluente derecho del Duero, donde además de semillas se ha identificado madera carbonizada de Vitis sp.: Castelinho (Seabra et al., 2020), Cidadelhe (Vaz et al., 2016a) y Quinta de Crestelos (Vaz et al., 2017). 
SPAL 30.1

(2021)

165-195

ISSN: $1133-4525$

ISSN-e: 2255-3924

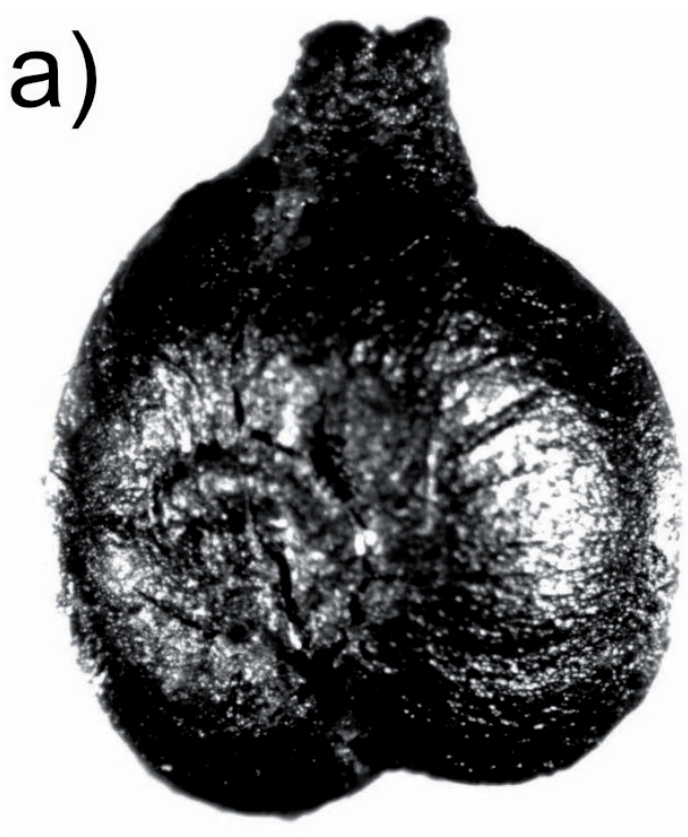

b)

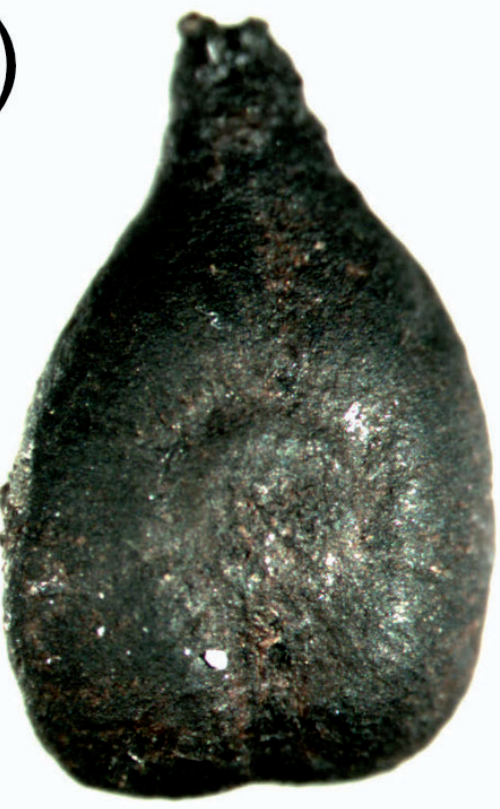

$1 \mathrm{~mm}$

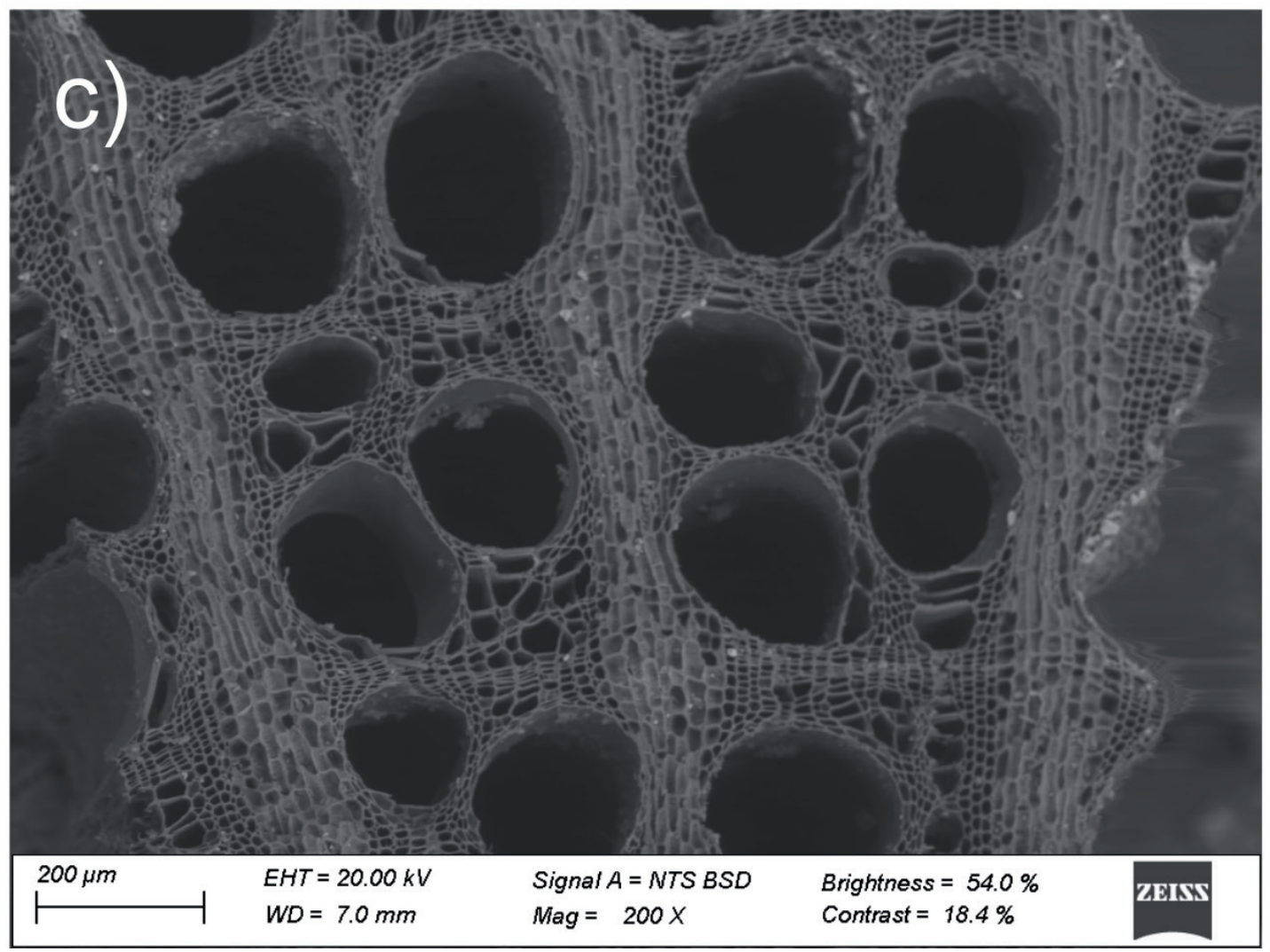

Los hallazgos de época romana -siglos I-V d.n.e.- son más abundantes y diversos. Se documentan restos carpológicos en castros con ocupaciones de esta fase como Cruito (Pinto da Silva, 1988), Briteiros (Tereso, 2012) o Monte Mozinho (Tereso, 2012), y en asentamientos de fundación romana: O Areal (Teira Brión, 2010), Tongobriga (López-Dóriga, 2020) y Reza Vella (Teira Brión, 2019), algunos de ellos asociados a tumbas de incineración en Bracara Augusta (Vaz et al., 2020). Encontramos semillas en la unidad agrícola o torcularium relacionada con la producción de vino de Foz da Ribeira do Poio (Tereso et al., 2018) y en el interior de estructuras de plantación de vid (Fontes y Magalhães, 2019). Resulta significativo el hallazgo de vid silvestre, interpretada como tal a través de su morfometría, en los yacimientos del castro de Penices (Figueiral, 1995), Reza Vella y O Areal (Boso et al., 2020). En este último yacimiento se han asociado 2 pepitas a Vitis vinifera subsp. sylvestris, aunque la mayoría del conjunto corresponde a la variedad doméstica Vitis vinifera subsp. vinifera. Los análisis de residuos han revelado trazas de vino en el interior de dos ánforas sumergidas en una playa de Esposende -Portugal- originarias del sur peninsular ibérico (Oliveira et al., 2015) y en una anforeta tardorromana del yacimiento de Rúa Ferreiría (Teira Brión, 2019). 
SPAL 30.1

(2021)

\section{$165-195$}

ISSN: $1133-4525$

ISSN-e: 2255-3924
Finalmente, la Alta Edad Media es el período en el que se ha recuperado un menor número de evidencias arqueobotánicas. Las únicas semillas encontradas proceden de la excavación de la Tabacalera de Gijón (Carrión Marco et al., 2015; Peña-Chocarro et al., 2015). La revisión del contexto de su pozo-cisterna propone asociar los restos identificados con el colapso de una estructura vinculada a la élite asturiana del VIII-IX d.n.e., (Vigil-Escalera Guirado, 2018), retrasando la cronología estimada y proponiendo una interpretación diferente al contexto social de la publicación original del yacimiento (Fernández Ochoa et al., 2015). En niveles tardorromanos de Castro Ventosa se han determinado granos de polen (López Merino et al., 2008). Además, de la ocupación medieval del castro de O Neixón Grande procede la identificación de madera carbonizada de Vitis (Barbeito Pose et al., aceptado).

Tabla 1. Referencias Vitis sp. en los registros polínicos de depósitos naturales en el Noroeste Ibérico (nd=no determinado)

\begin{tabular}{|c|c|c|c|c|c|c|}
\hline Yacimiento & Ref. Lab. & Años BP & BC/AD cal. $2 \alpha$ & Taxón & Análisis & Referencias \\
\hline \multirow[t]{3}{*}{ Pena da Cadela } & nd & $4620 \pm 80 \mathrm{BP}$ & $3632-3100 \mathrm{BC}$ & Vitis sp & Polen & (Mighall et al., 2006) \\
\hline & nd & $2630 \pm 70 \mathrm{BP}$ & $972-541 \mathrm{BC}$ & Vitis sp & Polen & (Mighall et al., 2006) \\
\hline & nd & $1980 \pm 60 \mathrm{BP}$ & $166 \mathrm{BC}-134 \mathrm{AD}$ & Vitis sp & Polen & (Mighall et al., 2006) \\
\hline \multirow[t]{2}{*}{ Villaviciosa } & nd & $4000 \mathrm{BP}$ & - & Vitis sp & Polen & (García Antón et al., 2006) \\
\hline & nd & $3000 \mathrm{BP}$ & - & Vitis sp & Antracología & (García Antón et al., 2006) \\
\hline $\begin{array}{l}\text { As Borralleiras da } \\
\text { Cal Grande }\end{array}$ & nd & $3850 \pm 70 \mathrm{BP}$ & $2547-2059$ BC & Vitis sp & Polen & (Mighall et al., 2006) \\
\hline Braña Rubia & nd & 2500-1600 BP & & Vitis sp & Polen & (Tornqvist et al., 1989) \\
\hline
\end{tabular}

Tabla 2. Identificación de Vitis en análisis arqueobotánicos de yacimientos arqueológicos del NW Ibérico (nd=no determinado).

\begin{tabular}{|c|c|c|c|c|c|c|c|c|}
\hline Período & Yacimiento & Datación & $\mathrm{BC} / \mathrm{AD}$ cal $2 \alpha$ & Cronología & Taxón & Análisis & Restos & Referencias \\
\hline 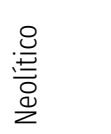 & Mamoa da Arcã & & & VI-III ka a.n.e. & Vitis vinifera & Carbón & nd & $\begin{array}{l}\text { (Figueiral y Sanches, 1998- } \\
\text { 1999) }\end{array}$ \\
\hline \multirow{2}{*}{ 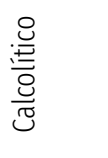 } & Buraco da Pala & $4120 \pm 80 \mathrm{BP}$ & $2887-2491 \mathrm{BC}$ & & Vitis $s p$ & Semillas & 5 & $\begin{array}{l}\text { (Ramil Rego y Aira Rodríguez, } \\
\text { 1993) }\end{array}$ \\
\hline & Crasto de Palheiros & & & & Vitis vinifera & Carbón & 1 & (Figueiral et al., 2017) \\
\hline \multirow{2}{*}{ 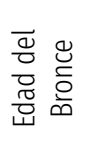 } & Freixo & & & & Vitis vinifera & Carbón & 1 & $\begin{array}{l}\text { (María Martín Seijo, comuni- } \\
\text { cación personal) }\end{array}$ \\
\hline & Terraço das Laranjeiras & & $1411-1257 \mathrm{BC}$ & & Vitis $s p$ & Pedicelos & 3 & (Jesus et al., 2020) \\
\hline 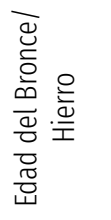 & Castelo de Matos & $\begin{array}{l}\text { OXA2146: } \\
2700 \pm 90 \mathrm{BP}\end{array}$ & $1116-559 \mathrm{BC}$ & & $\begin{array}{l}\text { Vitis vinifera } \\
s p\end{array}$ & Semillas & nd & $\begin{array}{l}\text { (Queiroga, 1992; Tereso et } \\
\text { al., 2016) }\end{array}$ \\
\hline \multirow{6}{*}{ 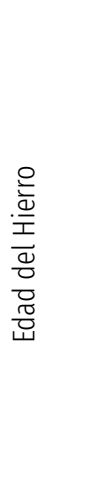 } & A Fontela & $2520 \pm 30 \mathrm{BP}$ & $795-542$ BC & & Vitis $s p$ & Polen & nd & $\begin{array}{l}\text { (Andrés Currás Domínguez, } \\
\text { comunicación personal) }\end{array}$ \\
\hline & São Julião & & & & Vitis $s p$ & Semillas & 1 & $\begin{array}{l}\text { (Aira Rodríguez y Ramil Rego, } \\
\text { 1995) }\end{array}$ \\
\hline & Crasto de Palheiros & & & VI-III a.n.e. & Vitis vinifera & $\begin{array}{l}\text { Semillas/ } \\
\text { Pedicelos }\end{array}$ & $3 / 3$ & (Leite et al., 2018) \\
\hline & Quinta de Crestelos & & & IV-III a.n.e. & Vitis vinifera & Semillas & 1 & (Vaz et al., 2017) \\
\hline & Crastoeiro & & & IV-II a.n.e. & Vitis vinifera & Semillas & 21 & (Seabra et al., 2018a, b) \\
\hline & Briteiros & & & II a.n.e. & Vitis $s p$ & Semillas & 14 & (Tereso, 2012) \\
\hline
\end{tabular}


SPAL 30.1 (2021)

\section{5-195}

ISSN: $1133-4525$ ISSN-e: 2255-3924

\begin{tabular}{|c|c|c|c|c|c|c|c|c|}
\hline Período & Yacimiento & Datación & $\mathrm{BC} / \mathrm{AD}$ cal $2 \alpha$ & Cronología & Taxón & Análisis & Restos & Referencias \\
\hline \multirow{4}{*}{ 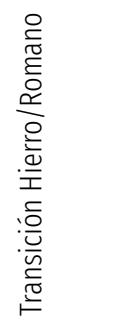 } & Crasto de Palheiros & & & $\begin{array}{l}\text { III a.n.e.-I } \\
\text { d.n.e. }\end{array}$ & Vitis vinifera & Semillas & 1 & (Leite et al., 2018) \\
\hline & Chã & & & II a.n.e.-I d.n.e. & Vitis & Semillas & 5 & (Vaz et al., 2016b) \\
\hline & Castelinho & & & II a.n.e.-I d.n.e. & Vitis sp. & $\begin{array}{l}\text { Semillas/ } \\
\text { Carbón }\end{array}$ & $56 / 4$ & (Seabra et al., 2020) \\
\hline & Quinta de Crestelos & & & II a.n.e.-I d.n.e. & Vitis vinifera & Carbón & 1 & (Vaz et al., 2017) \\
\hline \multirow{11}{*}{ 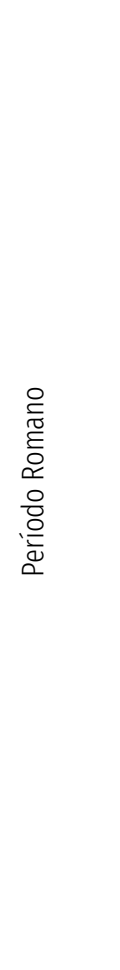 } & Castro de Cidadelhe & & & I a.n.e.-I d.n.e. & $\begin{array}{l}\text { Vitis vini- } \\
\text { fera }\end{array}$ & Carbón & 3 & (Vaz et al., 2016a) \\
\hline & Briteiros & & & I a.n.e.-I d.n.e. & $\begin{array}{l}\text { Vitis vini- } \\
\text { fera }\end{array}$ & Semillas & 20 & (Tereso, 2012) \\
\hline & \multirow{2}{*}{$\begin{array}{l}\text { Praia do Ribeiro de } \\
\text { Peralta }\end{array}$} & & & \multirow[t]{2}{*}{ | a.n.e.-| d.n.e. } & Vino & $\mathrm{GC} / \mathrm{MS}$ & 1 & (Oliveira et al., 2015) \\
\hline & & & & & Defructum & $\mathrm{GC} / \mathrm{MS}$ & 1 & (Oliveira et al., 2015) \\
\hline & Bracara Augusta & & & | a.n.e.-|| d.n.e. & Vitis vinifera & $\begin{array}{l}\text { Semillas/ } \\
\text { Carbón }\end{array}$ & $1 / 101$ & (Vaz et al., 2020) \\
\hline & Chã & & & | a.n.e.-I| d.n.e. & Vitis & Semillas & 10 & (Vaz et al., 2016b) \\
\hline & Castro de Penices & & & | a.n.e.-|| d.n.e. & $\begin{array}{l}\text { Vitis vinifera } \\
\text { subsp syl- } \\
\text { vestris }\end{array}$ & Semillas & 10 & (Figueiral, 1995) \\
\hline & Cruito & & & I d.n.e. & Vitis vinifera & Semillas & nd & (Pinto da Silva, 1988) \\
\hline & Foz da Ribeira do Poio & & & |-II d.n.e. & Vitis vinifera & Semillas & $>11$ & (Tereso et al., 2018) \\
\hline & San Cibrán de Las & $1855 \pm 30 \mathrm{BP}$ & $82-234 \mathrm{AD}$ & & Vitis vinifera & $\begin{array}{l}\text { Semillas/ } \\
\text { Pedicelos }\end{array}$ & $15 / 4$ & (Álvarez González, 2019) \\
\hline & Briteiros & & & \|-III d.n.e & Vitis vinifera & Semillas & 3 & (Tereso, 2012) \\
\hline \multirow{7}{*}{ 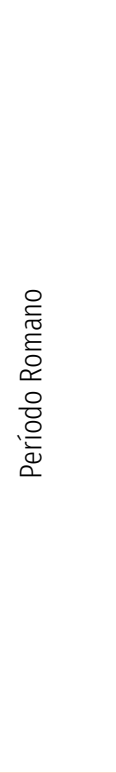 } & \multirow[t]{2}{*}{0 Areal } & \multirow[t]{2}{*}{$\begin{array}{l}\text { Beta-302977: } \\
1680 \pm 30 \text { BP }\end{array}$} & \multirow[t]{2}{*}{$258-422 A D$} & & $\begin{array}{l}\text { Vitis vinifera } \\
\text { subsp. vini- } \\
\text { fera }\end{array}$ & Semillas & 97 & $\begin{array}{l}\text { (Boso et al., 2020; Teira } \\
\text { Brión, 2019) }\end{array}$ \\
\hline & & & & & $\begin{array}{l}\text { Vitis vinifera } \\
\text { subsp. syl- } \\
\text { vestris }\end{array}$ & Semillas & 2 & $\begin{array}{l}\text { (Boso et al., 2020; Teira } \\
\text { Brión, 2019) }\end{array}$ \\
\hline & Monte Mozinho & & & III-IV d.n.e & Vitis vinifera & Semillas & nd & (Tereso, 2012) \\
\hline & Rúa Ferreiría 55 & & & III-IV d.n.e & Vino & $\mathrm{GC} / \mathrm{MS}$ & 1 & $\begin{array}{l}\text { (Alessandra Pecci, comunica- } \\
\text { ción personal) }\end{array}$ \\
\hline & Reza Vella & & & I-VI| d.n.e. & $\begin{array}{l}\text { Vitis vinifera } \\
\text { subsp syl- } \\
\text { vestris }\end{array}$ & Semillas & 1 & $\begin{array}{l}\text { (Boso et al., 2020; Teira } \\
\text { Brión, 2019) }\end{array}$ \\
\hline & $\begin{array}{l}\text { Bracara Augusta (Oficina } \\
\text { de S. José) }\end{array}$ & & & & Vitis $s p$ & Semillas & nd & (Fontes y Magalhães, 2019) \\
\hline & Tongobriga & & & & Vitis vinifera & Semillas & 1 & (López-Dóriga, 2020) \\
\hline$\frac{.0}{\overline{0}}$ & La Tabacalera & & & VIII-IX d.n.e. & Vitis vinifera & Semillas & 4 & $\begin{array}{l}\text { (Carrión Marco et al., 2015; } \\
\text { Vigil-Escalera Guirado, 2018) }\end{array}$ \\
\hline$\frac{\pi}{0}$ & Castro Ventosa & & & & Vitis $s p$ & Polen & nd & (López Merino et al., 2008) \\
\hline$\stackrel{巳}{\stackrel{E}{\leftarrow}}$ & O Neixón Grande & $1200 \mathrm{BP}$ & & VIII-IX d.n.e. & Vitis vinifera & Carbón & nd & $\begin{array}{l}\text { (Barbeito Pose et al., } \\
\text { aceptado) }\end{array}$ \\
\hline
\end{tabular}

\section{DISCUSIÓN}

La heterogeneidad de evidencias arqueobotánicas y yacimientos dibuja distintos escenarios en el aprovechamiento de la vid; escenarios que responden a comportamientos y a prácticas diferenciables territorialmente dentro del ámbito de estudio, pero que al mismo tiempo posibilitan entender la gestión local de la variedad silvestre (Vitis vinifera subsp. sylvestris) y la introducción y expansión de la vid doméstica (Vitis vinifera subsp. vinifera). 
SPAL 30.1

(2021)

\section{$165-195$}

ISSN: 1133-4525 ISSN-e: 2255-3924

\subsection{Vitis sylvestris en el Noroeste ibérico}

La vid silvestre se conoce en la península ibérica desde el Cuaternario (cf. Carrión, 2012). En el área mediterránea la mayor parte de las poblaciones se encuentran en bosques de ribera como planta trepadora a árboles tutores (Iriarte-Chiapusso et al., 2013). En el norte de clima atlántico húmedo puede encontrarse en posición coluvial, laderas, acantilados y playas (Iriarte-Chiapusso et al., 2013). A pesar de la dispersión de Vitis vinifera subsp. sylvestris en muchos de los territorios peninsulares, hoy en día (cf. Carreño Sánchez, 2005; Cunha et al., 2013) existe un vacío en el Noroeste. No obstante, durante la Protohistoria se encuentra bien atestiguada (tab. 1). Esta ausencia podría explicarse por la regresión de su medio natural durante los últimos milenios, fuertemente antropizado desde el Neolítico, y su alta sensibilidad a enfermedades como el mildiu (Boso et al., 2020).

La identificación de los caracteres diagnósticos de polen, carbones o semillas no siempre alcanza a determinar especies. En las semillas, el solapamiento de las morfologías y la deformación de los materiales arqueológicos durante la carbonización son dificultades a considerar (Bouby et al., 2013). En los últimos años se ha planteado que la morfometría puede resultar un indicador válido para discernir tipos de semillas (Boso et al., 2020; Orrù et al., 2013; Terral et al., 2010). La potencialidad de los análisis de ADN posibilitaría indagar en la proximidad genética de las poblaciones de vid del pasado. Sin embargo, estamos ante una disciplina que todavía necesita de desarrollo. A la ausencia de análisis genéticos sobre materiales arqueobotánicos en el Noroeste, se une el estado de preservación de los restos, mayormente carbonizados o muestras conservadas en medios húmedos con alta degradación del ADN. En función de estas limitaciones debemos valorar el contexto actual de la literatura sobre la vid en Iberia, que sugiere que todos aquellos hallazgos anteriores al I milenio a.n.e. corresponden a $\mathrm{V}$. sylvestris. Hipotéticamente, la vid silvestre se justificaría en varios depósitos naturales (tab. 1, fig. 6) y en muestras de yacimientos de la Protohistoria (tab. 2, fig. 6). Pero, además, recientes análisis morfométricos revelan que fueron gestionadas al menos hasta época romana (Boso et al., 2020).

Respecto a la distribución de la vid silvestre, observamos un rasgo espacial significativo. Está presente en depósitos naturales de regiones donde todavía no se ha determinado en muestras arqueológicas, como el área cantábrica, pero sí se ha recuperado en yacimientos de la cuenca del Duero, dentro de la región biogeográfica mediterránea. Esta disparidad puede deberse a una ilusión producida por la investigación arqueológica, que todavía no ha determinado polen en las regiones más meridionales pese a tener una mayor interacción humana. Aunque la presencia de pepitas o madera carbonizada es habitualmente una señal del transporte de plantas a los yacimientos, no es posible inferirlo directamente en todas las evidencias. Por ejemplo, el polen de vid de la muestra basal de la columna polínica de A Fontela (tab. 2, fig. 6) se interpreta por su presencia en el entorno o por contacto directo de partes de la planta con el sedimento de un pequeño paleocauce (Teira Brión, 2019). Quizás en este caso no exista relación entre ocupación y aprovechamiento. La dispersión e inclusión de restos arqueobotánicos protohistóricos indican la disponibilidad en el medio, pero no sus formas de consumo, al ser restos carbonizados habitualmente recuperados en depósitos secundarios o terciarios. Y aunque se haya aprovechado un recurso natural, no podemos descartar la gestión de las poblaciones de vid silvestre o su cuidado, de los que podrían derivar los carbones de sarmientos de algunos yacimientos (tab. 2, fig. 6). Aunque esta hipótesis 
SPAL 30.1

(2021)

\section{$165-195$}

ISSN: 1133-4525

ISSN-e: 2255-3924 debe tomarse con cautela, estas prácticas no fueron extrañas a lo largo del ámbito mediterráneo y dieron origen a viticulturas locales como han señalado varias publicaciones (cf. Arroyo-García et al., 2006; Bacilieri et al., 2017).

\section{2. ¿Cultivo y consumo de vino en el I milenio a.n.e.?}

En siglos finales de la Edad del Hierro varios asentamientos documentan Vitis, observándose un incremento en su frecuencia. No obstante, debe matizarse que la arqueología del Noroeste ha tenido una mayor atención e interés en este período, por lo que dicho incremento es consecuente con la historiografía de la investigación. A pesar de esta circunstancia, la variedad y cantidad de los datos sugieren una expansión del consumo de la vid en la segunda mitad del I milenio a.n.e., pero también surgen varias cuestiones en torno a la naturaleza de este consumo que necesitan de distintos escenarios para ser explicadas.

Una de las preguntas por resolver es cuándo se produce el cultivo de la vid doméstica (Vitis vinifera subsp. vinifera). Se ha propuesto la presencia de viñedo para regiones del centro de Portugal, vinculada a la influencia griega y púnica (Arruda, 2008), aunque el tipo de evidencia de estos hallazgos -semillas y polen- hace que deban tomarse con cautela, pues pueden corresponder a cepas silvestres. Así, por ejemplo la vid cultivada más próxima se encuentra en Castro Marim, en el sur de Portugal, donde se ha sugerido la existencia de un conjunto de semillas con poblaciones de la variedad doméstica y silvestre a partir de morfometría (Queiroz y Mateus, 2007). Las evidencias arqueobotánicas concentradas en la cuenca del Duero pueden explicarse, hipotéticamente, por una continuidad en las prácticas relacionadas con la recolección, gestión o, incluso, el cultivo de la vid silvestre. Resaltamos que lo doméstico, desde la disciplina de la biología, implica cambios en las plantas a partir de la selección de caracteres, pero cultivar o recolectar son acciones humanas que pueden ejercerse sobre una misma especie. Dicho esto, las variedades silvestres habrían podido cultivarse o trasplantarse a espacios antropizados sin que ello supusiera su domesticación.

No siempre resulta claro discernir si los restos de Vitis parten de prácticas locales o, por el contrario, están ligados a la adopción de costumbres y formas de consumo mediterráneas. A partir del siglo $V$ a.n.e. se registra la llegada de vinos selectos al Noroeste, fruto del intercambio comercial. Un ejemplo de ello es el borde de ánfora tipo MGS IV del Castro de O Neixón Grande, fabricado en la Magna Grecia o en la Sicilia Oriental en los siglos IV-III a.n.e. (García Fernández et al., 2020). Sin embargo, desconocemos si las ánforas que alcanzaban estas costas transportaban vino de manera habitual o excepcional. La razón es la falta de análisis que identifiquen los productos contenidos en los recipientes fenicio-púnicos provenientes del sur. El ciclo comercial más antiguo registrado con el área del Estrecho -finales del V y mediados del III a.n.e.- constata la llegada de ánforas al área de As Rías Baixas y, de manera esporádica, a la bahía de A Coruña. De entre todas ellas solo cabe el apelativo de vinarias y olearias para los contenedores anfóricos grecoitálicos, por el momento muy raros (Sáez Romero et al., 2019). El resto de los envases -T-8211, T-12111, T-8112 y Pellicer D- se vinculan formalmente a salazones ictícolas, a contenidos olearios y agropecuarios, respectivamente. En la literatura reciente se pone en duda el axioma de contendor/contenido y se les atribuye un uso polivalente, basándose sobre todo en la coyuntura poblacional, productiva y comercial de esta fase, en la cual Gadir se configuró como el puerto de salida de los excedentes comarcales de toda la Turdetania. Los análisis de contenidos, aunque aún exiguos en número, demuestran que los 
SPAL 30.1

(2021)

\section{$165-195$}

ISSN: 1133-4525

ISSN-e: 2255-3924 envases eran multifuncionales y un mismo tipo transportaba aceite, carne o derivados lácteos (García Fernández et al., 2016). Los estudios de procedencia de pastas, junto con las abundantes y geográficamente dispersas evidencias de infraestructuras productivas de ánforas, aseguran que su fábrica estaría vinculada a los productos alimentarios excedentes de cada comarca (García Fernández, 2019; Sáez Romero, 2010, 2018).

Otra importación destacada de esta fase comercial son las cerámicas de barniz negro. Procedentes de oficinas áticas, circulan por toda la fachada atlántica (cf. Arruda, 2007), poniendo de manifiesto un novedoso interés por incorporar maneras de estilo mediterráneo en la comensalidad festiva, si realmente coincidiese la función para la que fueron fabricadas con su uso real. De ser así, sería muy significativo el papel de las cráteras, un recipiente teóricamente orientado para el servicio del vino. Las situaciones varían según el área geográfica, asi en la región entre Duero y Miño la crátera de campana ática es la más solicitada (cf. Almeida et al., 1981; Carballo Arceo, 1987; Hidalgo Cuñarro, 1978; Naveiro López, 1991; Sanches, 2016) y excepcionalmente algún kylix (cf. Arruda, 2007). En cambio, en el litoral atlántico de As Rías Baixas hay un flujo constante de tinajas crateroides procedentes del Guadiana (Sáez Romero et al., 2019), al mismo tiempo que se fabrican imitaciones locales de crateroides de columnas (Rey Castiñeira, 2019) que recuerdan a las interpretaciones ibéricas definidas como tipo 9-A-II por Pereira Sieso (1988). Esta especial preferencia por las cráteras y crateriformes puede que sea realmente un reflejo de la llegada de vino, o tal vez solo evidencia el deseo de adquirirlo o de emular escenografías de su consumo, supliéndolo con otras bebidas propias. También es posible que no adquieran ni imiten cráteras por su vínculo funcional, sino que la razón fuera estética, el atractivo de lo exótico y de lo prestigioso. Así que, en definitiva, algunas tipologías de ánforas de esta fase comercial señalan que el vino mediterráneo llegaba hasta el Noroeste, pero en el estado actual de la investigación no demuestran fehacientemente que el vino fuese un producto importado masivamente antes del siglo II a.n.e. Los envases anfóricos son la evidencia tangible de una relación comercial, pero no indicativos directos del producto que circula. Sin análisis de contenidos, asimilar la función original de las vasijas áticas y turdetanas con su función real en los lugares de intercambio es una tarea compleja y pendiente.

En este momento de la Segunda Edad del Hierro, la vid también puede entenderse como un modelo iconográfico materializado en las arracadas de apéndice triangular o "de racimo" (cf. Parcero Oubiña et al., 2009; Pérez Outeiriño, 1982; Silva, 1986) extendidas por el mundo ibérico y meseteño (Delibes de Castro, 1994; Mata Parreño et al., 2010; Perea et al., 2010). La arracada de Vilar de Santos utiliza la vid como elemento simbólico al representar un racimo de uvas sujeto por el pico de un ave. Para Pérez Outeiriño (1982), los ornitomorfos del ejemplo de Vilar de Santos se corresponderían con aves acuáticas y estarian emparentados con tradiciones centro y norte europeas. Sin embargo, este modelo iconográfico se repite en el vaso con forma de pebetero de la diosa fenicia Tanit del santuario ibérico de La Luz -Murcia- (Lillo Carpio, 1991-1992). Fechada en la segunda mitad del siglo III a.n.e., la deidad porta arracadas en racimo y, en el tocado en forma de canister, incorpora dos figuras de aves confrontadas, posiblemente palomas asociadas a Astarté como símbolo agrario (Lillo Carpio, 1991-1992). Los apéndices de racimo podrían significar la aceptación de un gusto estético y técnico, mediante la aplicación de granulado, de influencia mediterránea, pero no necesariamente carente de significado. Así mismo, estas arracadas pueden comprenderse desde la fabricación o la adquisición de joyas de prestigio, bien de producción local o importadas, asociarse a la exaltación de 
SPAL 30.1

(2021)

\section{$165-195$}

ISSN: 1133-4525 ISSN-e: 2255-3924 productos con un alto estatus social -la vid-o funcionar como códigos simbólicos de un ideario religioso amalgamado en el seno de contactos interculturales.

La irrupción de Roma en la Península tuvo un impacto inmediato en las rutas comerciales atlántico-mediterráneas. La conquista del Noroeste fue un proceso dilatado, iniciado con la campaña militar de Décimo Junio Bruto -138-137 a.n.e.- y finalizado con las guerras cántabras en tiempos del emperador Augusto -28-19 a.n.e. No fue un único proceso sino, por el contrario, diverso, con contactos interculturales múltiples territorial y cronológicamente. Las evidencias arqueobotánicas de los siglos II-I a.n.e. se hallan en castros habitados por las sociedades de la Edad del Hierro, aún autogobernadas o en el inicio de la administración romana. Muchos contextos no aclaran este aspecto, lo que implica la posibilidad de varios escenarios simultáneos. De hecho, antes, durante y después de la conquista se promovieron relaciones de diferentes intensidades entre Roma y las comunidades locales. Así, la toma de Gadir en el 206 a.n.e. desemboca en la intensificación del comercio con ánforas provenientes del área del Estrecho (García Fernández et al., 2020). Estos materiales serían masivos en el Noroeste desde finales del II a.n.e. hasta mediados del I a.n.e., entre ellos formas identificadas como contenedores de vino -Lamboglia 4 y Dressel 1-, y, en el período entre mediados del I a.n.e. y mediados del I d.n.e., de Haltern 70 procedentes de la Bética y formas Dressel 2-4 y Pascual 1 de procedencia Tarraconense (Naveiro López, 1991; Suárez Piñeiro, 2005). Los análisis de residuos llevados a cabo sobre estos contenedores han determinado defructum en el interior de una Haltern 70 y vino dulce en urceus, que pueden fecharse entre la segunda mitad del siglo I a.n.e y el siglo I d.n.e., ambas producciones cerámicas del sur peninsular (Oliveira et al., 2015). Estos indicios supondrían la consolidación de un consumo de vino de importación vinculado al dominio romano de las rutas comerciales atlánticas.

Un escenario múltiple, con un consumo de vino adquirido comercialmente sin que suponga la introducción contrastada de prácticas agrícolas nuevas, junto con una gestión de la vid silvestre en la cuenca del Duero, es el que, quizás, mejor responde a las distintas cuestiones que se suceden durante el I milenio a.n.e. Los centros consumidores de los vinos del Mediterráneo habrían sido mayormente castros marítimos y del área de influencia del litoral occidental, con una penetración decreciente hacia el interior. Por el momento, nada indica que este consumo haya sido habitual o socialmente asequible hasta el siglo II a.n.e. La gestión de la vid en el área meridional o suroriental se habría basado en las cepas silvestres, sin que podamos aportar, en el estado actual de la cuestión, argumentos lo suficientemente sólidos para fijar la llegada de cepas domésticas durante la Edad del Hierro. En el período II-I a.n.e. la mayor frecuencia de semillas en el área meridional, la conquistada más prontamente, podría sugerir que la introducción o influencia romana en el cultivo de vitis vinifera subsp. vinifera sea hoy en día la hipótesis más robusta.

\subsection{Producción y consumo de vino durante época romana}

El cultivo de cepas domésticas se constata durante época romana (tab. 2, fig. 4, fig. 6). Los análisis morfométricos han identificado semillas de Vitis vinifera subsp vinifera y de Vitis vinifera subsp sylvestris en O Areal y Reza Vella (Boso et al., 2020), siendo factible que se estuviesen cultivando conjuntamente variedades domésticas y ancestros silvestres, creando contextos potenciales de hibridación. Aunque las líneas de investigación en morfometría no permiten discernir entre ellas con total precisión, sí 
SPAL 30.1

(2021)

165-195

ISSN: $1133-4525$

ISSN-e: 2255-3924

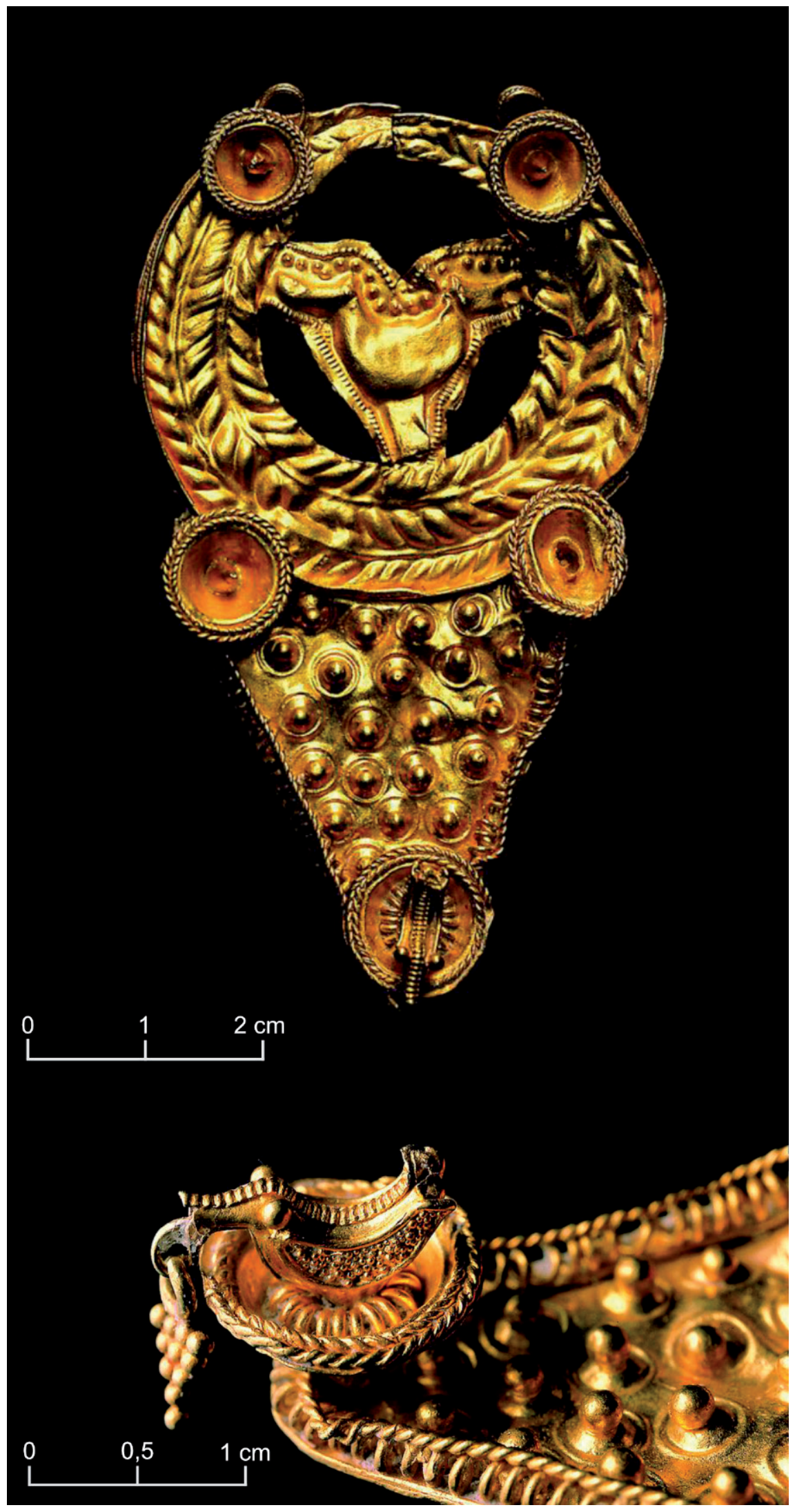

Figura 3. Arracada de Vilar de Santos. Pieza completa y detalle del extremo inferior del apéndice decorado con un ornitomorfo sujetando un racimo (Fuente: Museo Arqueolóxico Provincial de Ourense). posibilitan considerar la hibridación y el cultivo conjunto como cuestiones a explorar; cuestiones que parecen tener cierto apoyo en trabajos recientes de ADN. Así, se ha señalado la contribución de genes de las variedades de V. sylvestris dentro de las cultivadas en la Península (Andrés et al., 2012; Arroyo García y Revilla, 2013), en zonas del sur de Francia (Ramos-Madrigal et al., 2019), y son varios los yacimientos de la Protohistoria en los que se han encontrado conjuntos carpológicos con semillas de ambas especies (Ucchesu et al., 2015).

La producción de vino se desarrolla en el siglo I d.n.e en los valles meridionales (fig. 6). En el valle del Duero se fundan varias estructuras de producción de vino (cella vinaria): por ejemplo Fonte do Milho en el I d.n.e. (Almeida, 2006), Rumansil I datado en el III d.n.e. (Sá Coixão y Silvino, 2006) y se documenta una posible prensa próxima al centro del castro de Monte Mozinho (Tereso et al., 2013b). En la ribera del río Sabor, el yacimiento de Foz da Ribeira do Poio se ha interpretado como un torcularium de los 
SPAL 30.1

(2021)

\section{$165-195$}

ISSN: $1133-4525$

ISSN-e: 2255-3924 siglos I/II d.n.e. (Tereso et al., 2018). Los datos para el área septentrional son todavía inconsistentes, pero los hallazgos de San Cibrán de Las (Álvarez González, 2019) y la propuesta de datación entre mediados del I d.n.e. al III/IV d.n.e. para el lagar del castro de Astariz (Pérez Losada, información oral citada en Peña Cervantes, 2019) podrían indicar una fecha próxima en el tiempo para la cuenca del Miño, aunque más sólida a partir de los siglos II-III d.n.e. (tab. 2, fig. 6). La expansión del viñedo llega hasta regiones más próximas al litoral occidental. Aquí es donde encontramos trazas de vino en cerámicas y evidencias de sistemas de plantación de vid (Fontes y Magalhães, 2019; Teira Brión, 2010). Las zanjas de Rúa Ferreiría 59 del III-IV d.n.e., bajo un horizonte de abandono datado en 401-540 cal AD -CNA1503: 1595 \pm 30 BP-, son zanjas de en torno a 1 metro de longitud dispuestas en hileras paralelas separadas aproximadamente 2 metros y en ocasiones cortadas transversalmente. Otras zanjas yuxtapuestas señalan la existencia de superposiciones y remodelaciones del espacio. Las negativas corresponden a estructuras de plantación tipo alveus (Boissinot, 2001), descritas por Plinio (Plin. Nat. 17.35), que presentan paralelos en yacimientos peninsulares ibéricos (Echevarría Sánchez y Vera Rodríguez, 2015) y en Europa Occidental. Además, se han documentado negativas y fragmentos cerámicos de dolia de almacenaje. Aunque no se han analizado, dichos recipientes fueron empleados en la Antigüedad, entre otros usos, como contenedores de vino. En la Oficina de S. José encontramos otro ejemplo de una extensa plantación de viña tipo alveus con una cronología en la transición entre el período romano y la Edad Media. Se constituye por zanjas de sección en $U$ distribuidas regularmente y en cuyo interior se han hallado semillas de vid (Fontes y Magalhães, 2019). Oficina de S. José y Rúa Ferreiría son colindantes a los núcleos de fundación romana de Bracara Augusta y Aquis Celenis respectivamente y podrían abastecer un consumo local.

A partir del siglo I d.n.e. la llegada de ánforas vinarias habría decrecido repentinamente, y a juzgar por los nuevos hábitos de mesa - piezas de vajilla de mesa como jarras, vasos o copas- su consumo pudo haber continuado atendido por una oferta local (Suárez Piñeiro, 2005). A lo largo del período bajoimperial se asiste a una intensificación de la producción de vino en varios lugares de la Península, en torno a un proceso de concentración de la propiedad y autoabastecimiento, menos dependiente de las rutas comerciales mediterráneas (Peña Cervantes, 2005-2006). Una anforeta analizada en Rúa Ferreiría contenía trazas de haberse impermeabilizado con resina de Pinaceae y almacenado vino (Teira Brión, 2019). Si bien puede interpretarse que recipiente y contenido pueden ser objeto de un intercambio comercial, teniendo en cuenta la plantación de viña en el yacimiento podría haberse usado o reutilizado para almacenar la producción local (Teira Brión, 2019).

Los pocos ejemplos de contextos productivos se agrupan en torno a explotaciones rurales agricolas tipo villa. Estas explotaciones, vinculadas a familias pudientes, se conocen por toda la Península (cf. Noguera Celdrán y Antolinos Marín, 2011-2012). Por lo tanto, la producción de vino se habría sostenido principalmente en los nuevos asentamientos surgidos a raíz de la conquista, posiblemente destinado a satisfacer el consumo de los núcleos urbanos (Teira Brión, 2019) y significando, por tanto, un cambio del modelo de explotación heredado de la Edad del Hierro. Resulta significativo que la distribución espacial en áreas de estas evidencias se produzca en las mismas en las que ha pervivido hasta hoy en día un cultivo de la vid orientado a la producción comercial, aun siendo explotaciones familiares. Estas áreas vitivinícolas conocidas a través de la documentación en la Edad Media podrían haberse configurado ya en época romana. 
SPAL 30.1

(2021)

\section{$165-195$}

ISSN: 1133-4525

ISSN-e: 2255-3924
Tabla 3. Representaciones iconográficas mencionadas en el texto.

\begin{tabular}{|c|c|c|c|c|c|}
\hline Cronología & Elemento & Ámbito & Iconografía & Soporte & Procedencia \\
\hline Edad del Hierro & $\begin{array}{l}\text { Arracada de Vilar de } \\
\text { Santos }\end{array}$ & Adorno, simbólico & Racimo de vid & Oro & Vilar de Santos, Ourense \\
\hline \multirow[t]{5}{*}{ Período Romano } & $\begin{array}{l}\text { Estela de Iulius Seve- } \\
\text { rianus }\end{array}$ & Funerario & Racimo de vid & Granito & $\begin{array}{l}\text { Sobrado dos Monxes, A } \\
\text { Coruña }\end{array}$ \\
\hline & Estela de Severa & Funerario & $\begin{array}{l}\text { Racimo de vid / Repre- } \\
\text { sentación de Dioniso }\end{array}$ & Granito & Vigo, Pontevedra \\
\hline & Placa de Amiadoso & Decorativo, desconocido & Zarcillos y hojas & Mármol & Allariz, Ourense \\
\hline & Santa Baia de Bóveda & Decorativo, posible lugar de culto & Racimos de uva tinta & Pintura & Lugo \\
\hline & $\begin{array}{l}\text { Estatua de A Moura- } \\
\text { della }\end{array}$ & Decorativo, simbólico & $\begin{array}{l}\text { Representación de } \\
\text { Dioniso }\end{array}$ & Mármol & Verín, Ourense \\
\hline
\end{tabular}

Una de las razones de la expansión del viñedo en el Noroeste fue la importancia del vino como un elemento de socialización en la vida romana. La bebida, en aquellas sociedades donde esta existe, es primero un acto social que se produce en contextos de interacción personal, está regida por reglas culturales que determinan aspectos como lo que puede beberse, el momento y el lugar de los eventos de consumo de alcohol, el género y edad de la persona que la consume y el comportamiento específico y apropiado en cada contexto (Dietler, 1998). La vajilla de servicio en torno a la comensalidad (cf. Naveiro López, 1991) y ciertos objetos y elementos figurativos (tab. 3) nos desvelan el papel del vino dentro de actos de agregación social en este período. Conocemos representaciones de uvas que hacen referencia a ritos donde el vino está presente. Así, por ejemplo, en inscripciones dedicadas a los dioses Manes es frecuente la mención a Dioniso (cf. Suárez Piñeiro, 2005) y en varios soportes pétreos se representan partes de la vid. En la estela de Severa (Díez Platas, 2003), bajo una arquería geminada aparecen dos personajes que podrían retratar a Dioniso y al sátiro Ampelos, que sobre su cabeza sostiene una crátera de volutas y en su mano un racimo de uvas (fig. 5). La estatua de A Mouradella, realizada en mármol importado (González Soutelo et al., 2014) y datada en los siglos II-III d.n.e. se ha interpretado también como la imagen de Dioniso y Ampelos (García y Bellido, 1969). Según paralelos iconográficos, Dioniso encarnaría un estado de ebriedad y se apoyaría en Ampelos (Díez Platas, 2003). La representación escultórica de este pasaje secundario de la Eneida como la del dios del vino y el sátiro ha sido objeto de crítica (Díez Platas, 2003). Otro ejemplo es la estela funeraria de Iulius Severianus procedente del campamento militar romano de A Ciadella, en cuyo campo iconográfico se ha tallado una figura antropomorfa, un équido y un racimo de uvas (Suárez Piñeiro, 2005). Una cepa de vid creciendo del interior de una crátera gallonada es el motivo escogido para una de las cinco caras decoradas de la placa de Amiadoso (fig. 5). Realizada en mármol local, su cronología se ha estimado en el siglo II o en el IV d.n.e. (González Soutelo et al., 2016). Dado el realismo de la hoja de vid representada, es posible que se basase en un modelo real.

Las pinturas murales de Santa Baia de Bóveda nos ofrecen una idealización o codificación de un sistema de pensamiento, donde los racimos de uva tinta aparecen juntamente con aves como ocas, ánades, faisanes, perdices, gallos o pavos reales, dentro de un patrón compositivo enmarcado por un ajedrezado de motivos vegetales. A pesar de la larga trayectoria de investigación científica, hoy en día no parece estar del todo resuelto el origen y significado del yacimiento, siendo varias las interpretaciones del lugar (Carrocera Fernández, 2016; Montenegro Rúa, 2016). Si bien hay consenso en el origen romano de la construcción del edificio y de la fabricación de los ladrillos de la 
SPAL 30.1 (2021)

$165-195$

ISSN: $1133-4525$

ISSN-e: 2255-3924

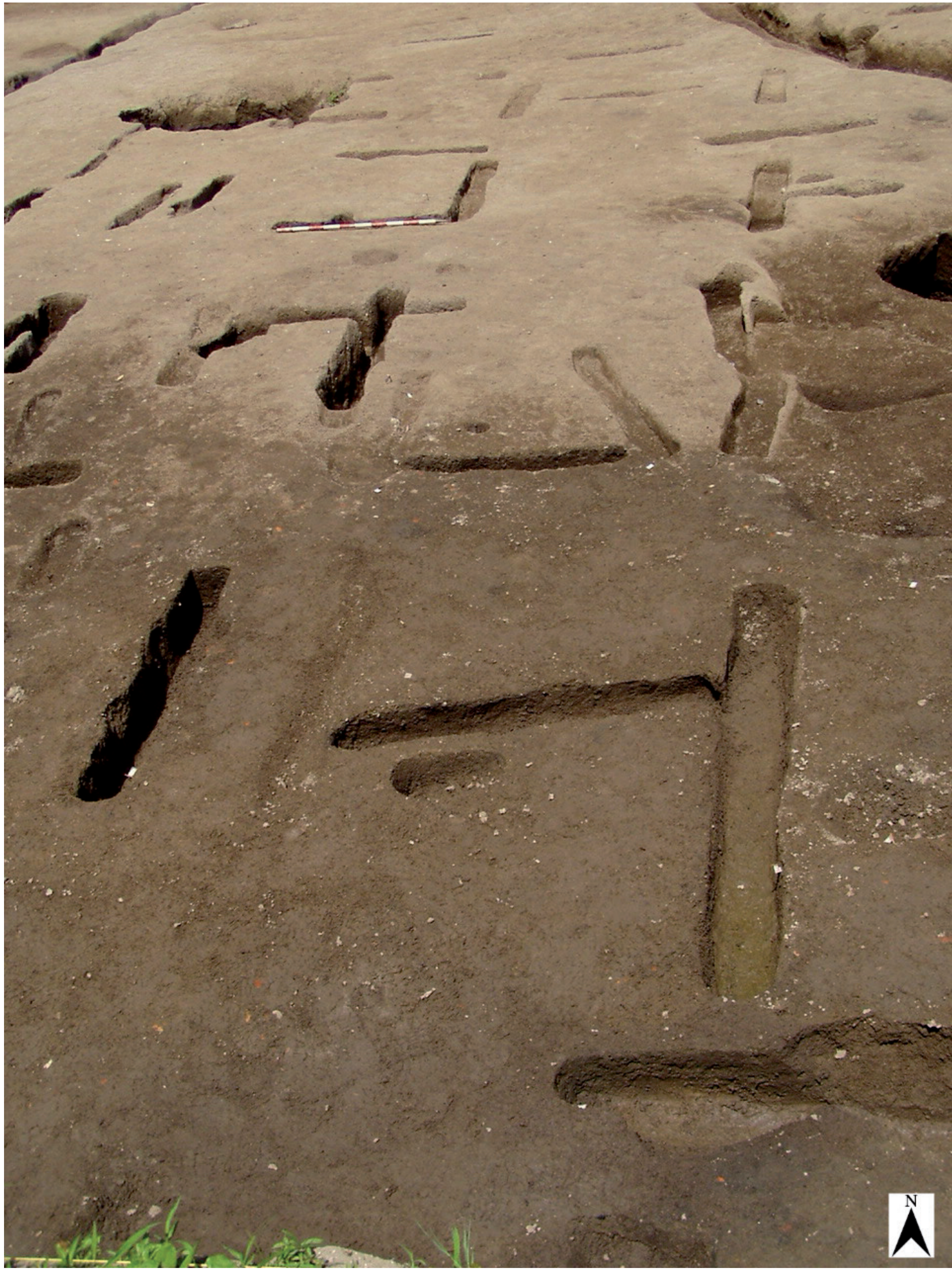

bóveda (Blanco-Rotea et al., 2009; Montenegro Rúa, 2016; Vidal Caeiro, 2006), se ha sugerido la reutilización de estos materiales en épocas posteriores (Vidal Caeiro, 2003, 2006) y propuesto retrasar la cronología de las pinturas hasta la Alta Edad Media, a través del análisis de los morteros y la lectura estratigráfica de sus paramentos (Blanco-Rotea et al., 2009). Algunos trabajos consideran la existencia de dos momentos pictóricos diferenciados. Uno sería el programa pictórico de la bóveda interior en el siglo IV d.n.e, que 
SPAL 30.1

(2021)

\section{$165-195$}

ISSN: 1133-4525 ISSN-e: 2255-3924 englobaría la compartimentación geométrica que incluye aves y racimos de uvas, y otro altomedieval del siglo IX d.n.e. con la fábrica de un casetonado pintado perteneciente a la construcción de la iglesia altomedieval posterior (Carrocera Fernández, 2016).

Si bien la existencia de representaciones figurativas puede en ocasiones ser la imitación de un modelo iconográfico común en la geografía peninsular ibérica, no la existencia directa de viñedos, la recurrencia de todas estas representaciones y su contexto en asentamientos de fundación romana señalan ritualidades y simbologías de la semiótica del consumo del vino implantados en espacios y escenarios arreglados en el seno de la concepción cultural romana de la bebida.

\subsection{El cultivo de la vid en época altomedieval}

Existen pocos datos arqueobotánicos para un período donde son abundantes las fuentes documentales, particularmente en la Baja Edad Media. Esto puede ser explicado por la menor atención sobre los restos vegetales en las intervenciones arqueológicas en yacimientos de época histórica, no solo en el Noroeste, sino que es un rasgo observado en toda la península ibérica (cf. Peña-Chocarro et al., 2019; Teira Brión, 2015). Entre los hallazgos destaca la presencia de pepitas de uvas en contextos arqueológicos del Cantábrico, aún sin poder aventurar si se trata de un cultivo local cuya expansión se habría producido en este momento o con anterioridad, y la continuidad en el área costera de Rías Baixas con la identificación de carbones de madera de Vitis en el yacimiento de 0 Neixón Grande (Barbeito Pose et al., e.p., aceptado).

El conjunto de la Tabacalera de Gijón nos posibilita teorizar sobre el rol social de la vid. En su interior se recuperaron elementos de banquete que pueden entenderse como formas de representación de poder y materiales que visibilizan distinción, prestigio o estatus (Vigil-Escalera Guirado, 2018). Por lo tanto, el origen de la vid del pozo-cisterna podría vincularse a los hábitos alimenticios de la nobleza asturiana del VIII d.n.e. (cf. Vigil-Escalera Guirado, 2018). Este contexto guarda similitudes con dinámicas que suceden en la Alta Edad Media. En torno al siglo VII d.n.e. se produce un momento de expansión y crecimiento poblacional unido al fortalecimiento de las élites locales (Sánchez Pardo, 2008). Estas familias o grupos de poder habrían acumulado amplias posesiones de tierra diseminadas y dispersas, como se aprecia en la documentación más tardía del siglo IX d.n.e. (Sánchez Pardo, 2008, 2010). Ya en la Baja Edad Media, el viñedo sería una de las grandes apuestas de la colonización agraria ligada al establecimiento del orden político y socioeconómico feudal, sobre el que intervienen activamente con políticas económicas que fomentan su cultivo y dotan de un marco legal a los procesos de elaboración, distribución y consumo (Rodrigo-Estevan, 2016). Esta importancia económica tuvo su reflejo en el Noroeste en las continuas referencias a las plantaciones de viñedo como una de las exigencias en los contratos de foro (cf. Portela Silva, 1976). Las explotaciones familiares pagaban parte de la producción de vino a la nobleza, que a su vez lo introducía en los mercados. Ejemplo de ello es el comercio de los caldos del Noroeste dentro de las grandes rutas marítimas que enlazaban el Atlántico con el Mediterráneo (Ferreira Priegue, 2005) a través de los puertos del Cantábrico, constituidos en nodos del tráfico mercantil (Solórzano Telechea, 2018). En este circuito, ciudades como Pontevedra y Oporto redistribuían los vinos de los valles del Miño y del tramo final del Duero al norte de Europa (Barros, 2004, Ferreira Priegue, 2005). 
SPAL 30.1 (2021)

$165-195$

ISSN: $1133-4525$

ISSN-e: 2255-3924

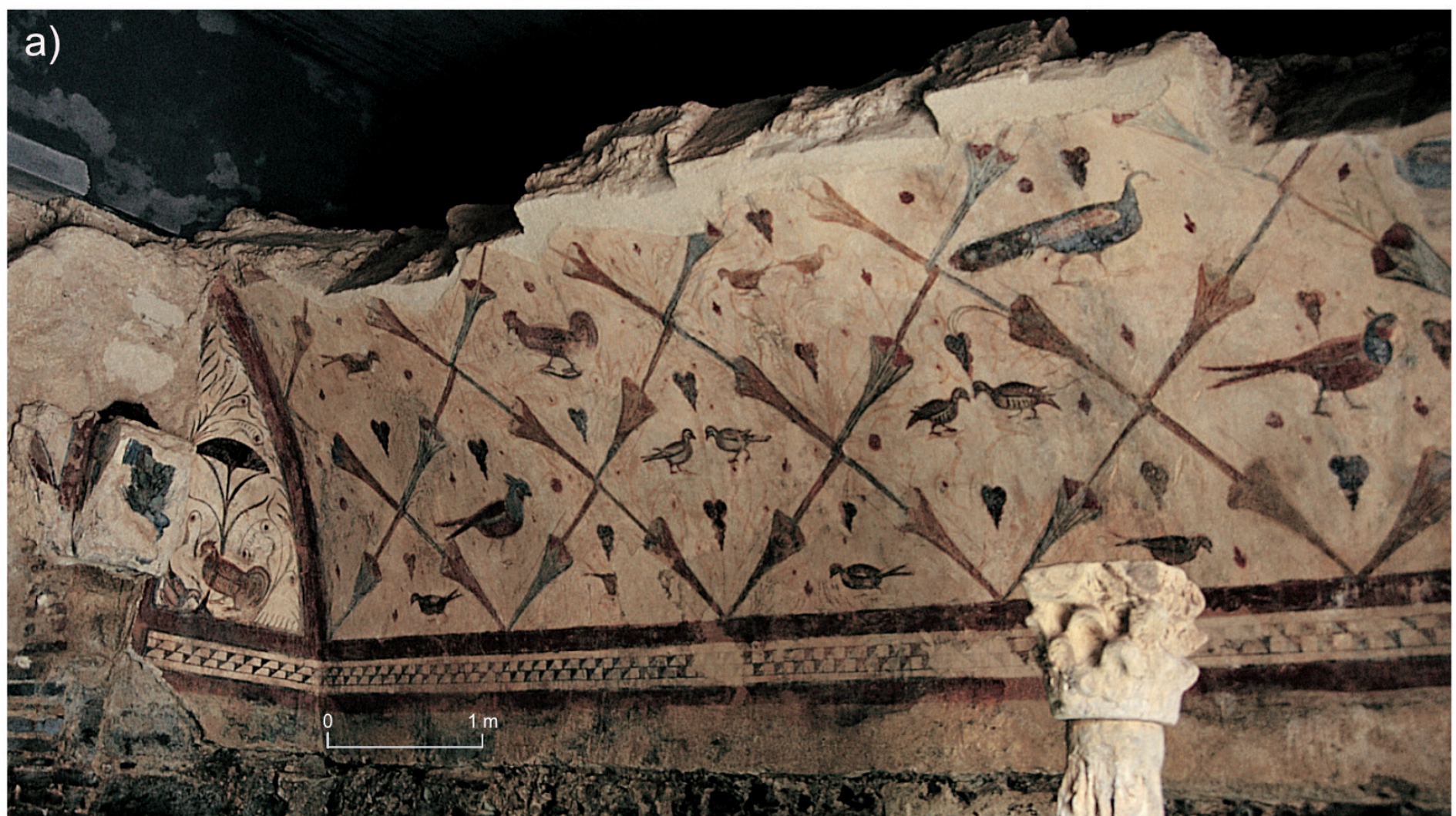

b)
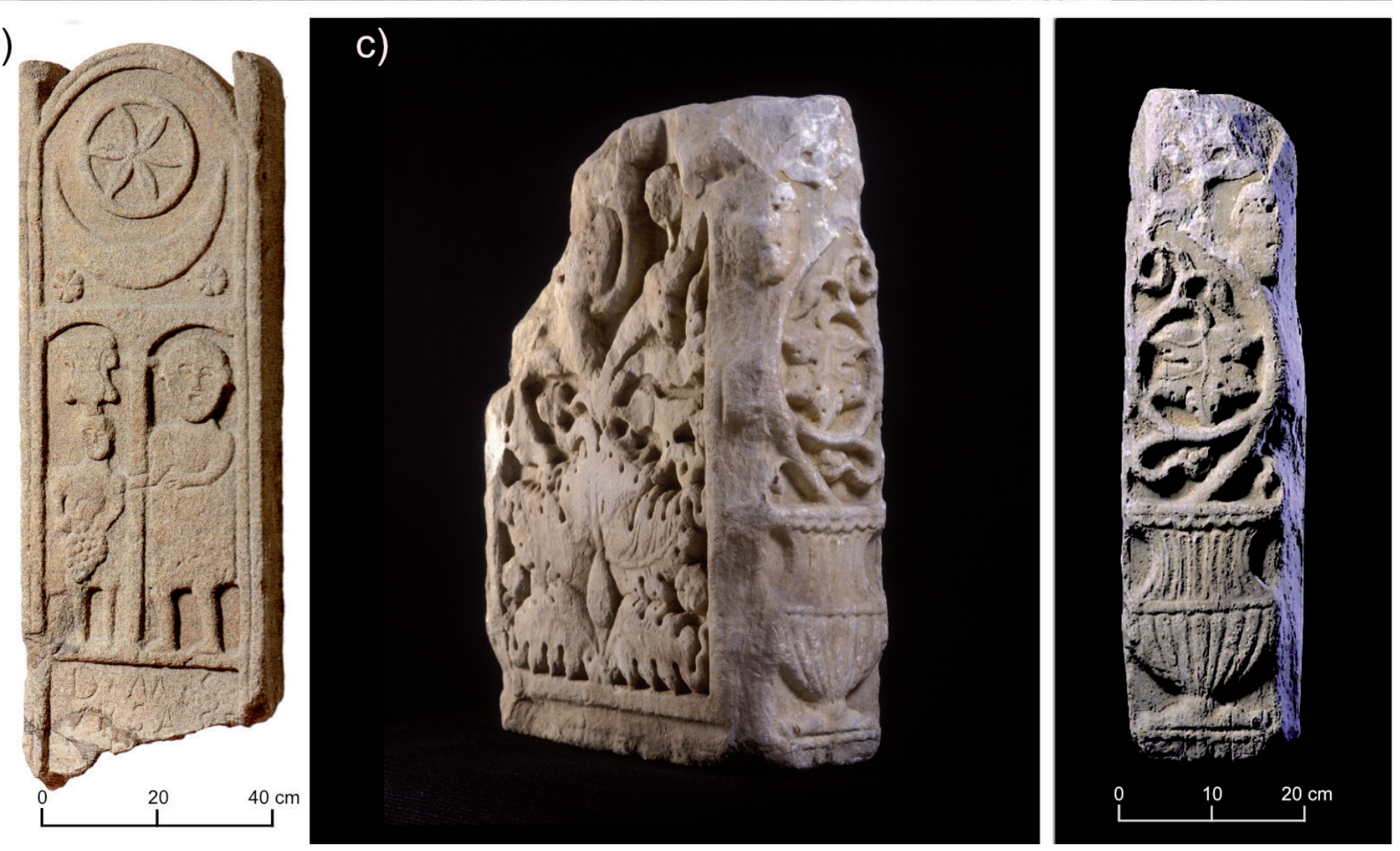

Figura 5. a) Pintura mural de la bóveda interna de Santa Baia de Bóveda con representación de un enrejado vegetal (trellis) racimos de uva y aves (fuente: Xulio Carballo Arceo). b) Estela de Severa (fuente: Museo Municipal Quiñones de León). c) Diferentes vistas de la representación una cepa de vid creciendo en el interior de una crátera de la placa de Amiadoso (fuente: Museo Arqueolóxico Provincial de Ourense).

Lo fragmentario de las evidencias arqueobotánicas en la Alta Edad Media conduce a teorías frágiles en torno a la elaboración de vino. El uso de otras fuentes permite acotar más esta producción. Así, en los últimos años se han originado avances en la investigación de los lagares rupestres excavados en roca, empleados para el pisado y prensado de la uva. Dichas estructuras están mayormente carentes de un contexto arqueológico que pueda datarse. Para el Noroeste, las propuestas cronológicas remiten a un amplio arco temporal que va desde el periodo romano hasta época moderna (Brun, 2004; Llana Rodríguez et al., 2011; Peña Cervantes, 2019), basados en pocos casos y con problemas para establecer interpretaciones evolutivas y sincronías de uso. El emplazamiento 
SPAL 30.1

(2021)

\section{$165-195$}

ISSN: 1133-4525 ISSN-e: 2255-3924 de los lagares nos permite ciertos razonamientos puesto que, generalmente, se sitúan alejados de los núcleos poblacionales. Esta característica supondría que las cepas asociadas a las prensas no ocupaban los terrenos más productivos de fondo de valle y su emplazamiento respondería a la proximidad entre el viñedo y los trabajos de prensado de la uva. Una vez transformada en mosto o vino, la producción debía transportarse. La propiedad y el modelo de explotación ofrecen muchas cuestiones abiertas. Potencialmente podrían gestionarse tanto como explotaciones de unidades familiares como a modo de monocultivo en manos de grandes propietarios. Lo que sí parece dibujarse a raíz de la distribución de los lagares es su pertenencia a un modelo desarrollado en las cuencas del Duero y del Miño/Sil. El vacío en el área septentrional y en el litoral quizás responda a otro modelo de economía, de viñedo o de propiedad, dado que yacimientos como O Areal, Rúa Ferreiría y O Neixón Grande muestran la continuidad del viñedo desde la Antigüedad (tab. 2). Quizás, a pesar de los vacíos y los problemas de datación, la distribución espacial de los lagares sería resultado de un proceso de cambio del sistema de explotación tardorromano, de cara a una producción en el seno de una realidad socioeconómica en transformación en época medieval (cf. Peña Cervantes, 2005-2006). Un cambio, rastreable en numerosos ejemplos de la Europa Occidental, que implicó la concentración de tierras en manos de grandes propietarios entre los que se incluyó la Iglesia (cf. Lewit, 2020).

\section{CONCLUSIÓN}

En la última década, el incremento de la información arqueobotánica nos ha permitido un mejor conocimiento de la explotación y consumo de la vid en el Noroeste de la península ibérica. Su análisis, en conjunto con otras evidencias, muestra comportamientos y evoluciones diferenciadas de los sistemas socioeconómicos imbuidos en el cultivo de Vitis vinifera subsp. vinifera y de la gestión de Vitis vinifera subsp. sylvestris desde la Protohistoria hasta la Alta Edad Media.

Durante la Edad del Hierro asistimos a varios procesos simultáneos. Uno está referido a un consumo local, ligado posiblemente a la gestión de la variedad silvestre, con una mayor incidencia en el área meridional y, quizás, con una tradición continuista de períodos anteriores. Otro se vincula a la llegada hipotética de vino y otros productos a través del comercio con el área del Estrecho, que se habría intensificado a finales del I milenio a.n.e. Finalmente, a modo de cuestión aún por resolver, la existencia o no de vid doméstica entre el Miño y el Duero, favorecida por la interculturalidad entre púnicos y comunidades locales o, bien, gracias a la influencia romana. Los registros actuales no son concluyentes para establecer el cultivo de V. vinifera durante la Edad del Hierro, pero son suficientemente ubicuos en contextos de los siglos II-I a.n.e. como para conjeturar sobre una introducción desde los primeros momentos de integración al estado romano.

Los datos arqueobotánicos respaldan el cultivo de la vid en época romana en el área meridional de la cuenca del Duero, en la cuenca media del Miño/Sil y el litoral occidental. Si bien es arriesgado determinar la sociología de su cultivo, los yacimientos estudiados indican paralelismos con los modos de producción documentados en otras zonas de la Península, aunque a menor escala. Respecto de las prácticas agrícolas, resulta interesante la presencia sincrónica de semillas de las variedades doméstica y silvestre. Quizás, la coexistencia de ambas variedades nos hable de la persistencia de variedades vinícolas locales anteriores a la conquista y un proceso de hibridación local. 


\section{SPAL 30.1 $(2021)$}

\section{$165-195$}

ISSN: $1133-4525$

ISSN-e: 2255-3924 a) depósitos naturales

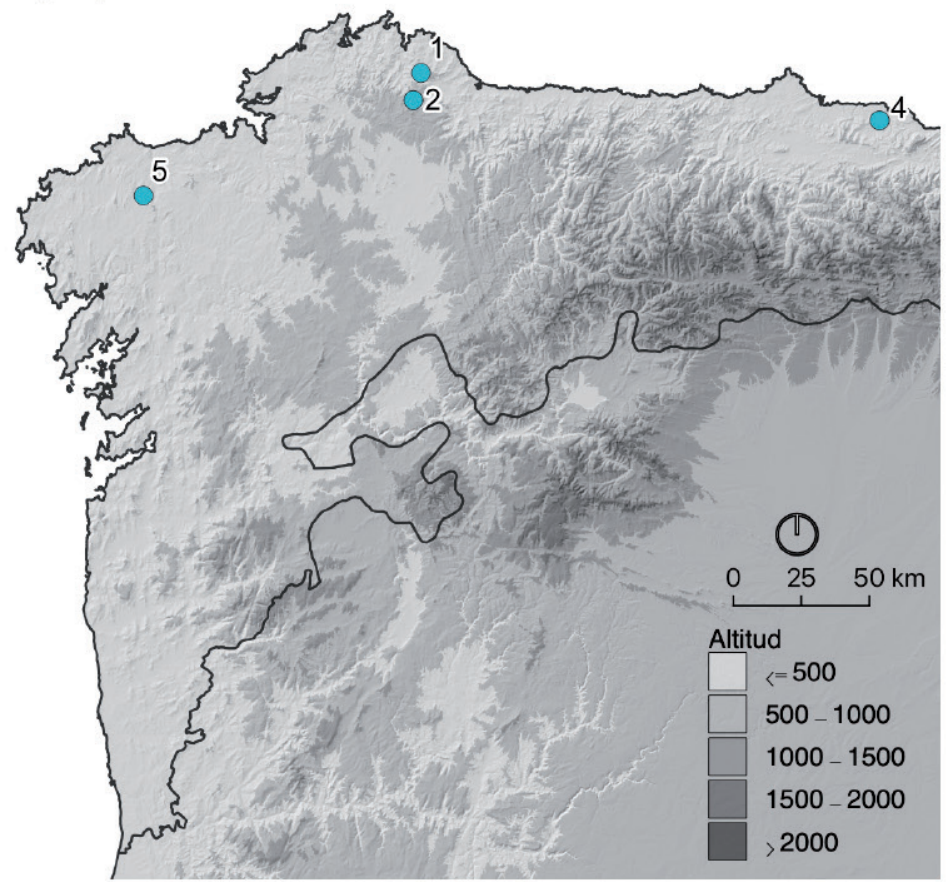

c) Edad del Hierro

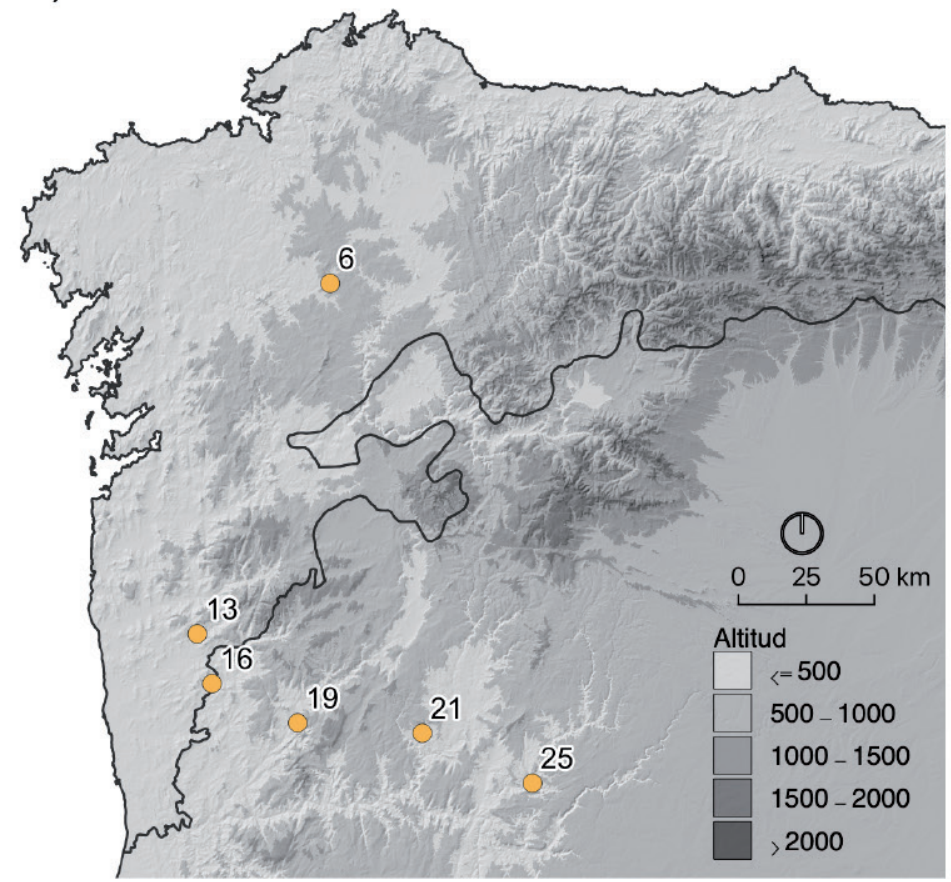

e) Alta Edad Media

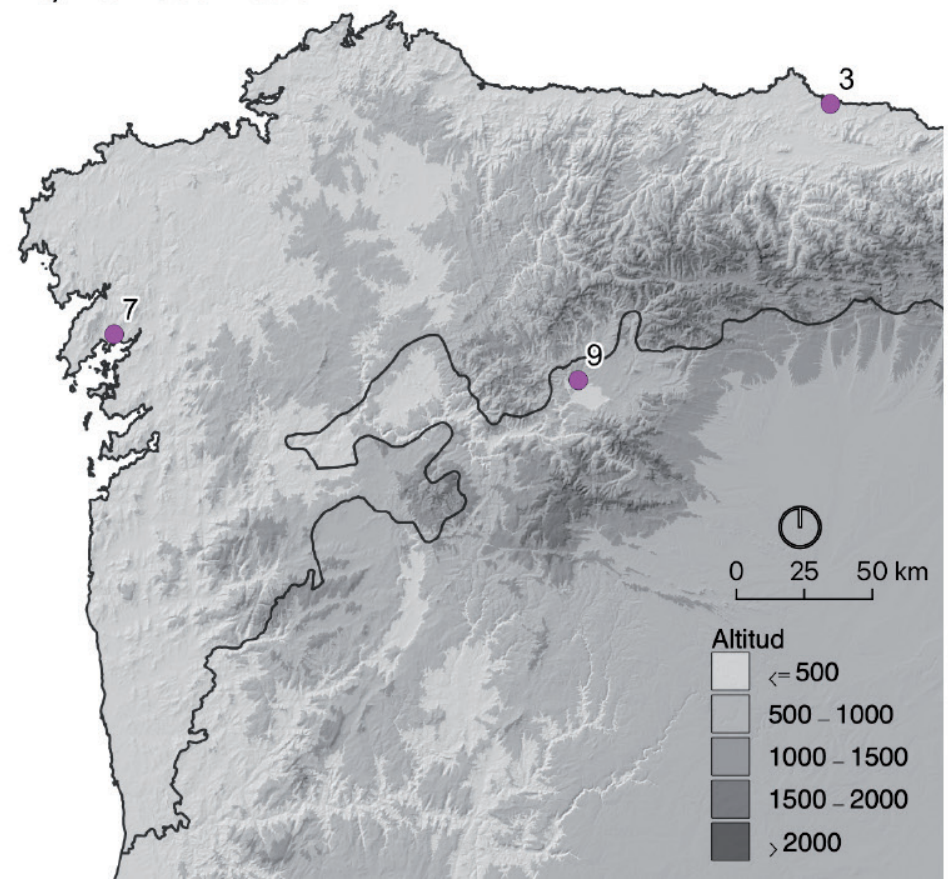

b) Neolítico-Edad del Bronce

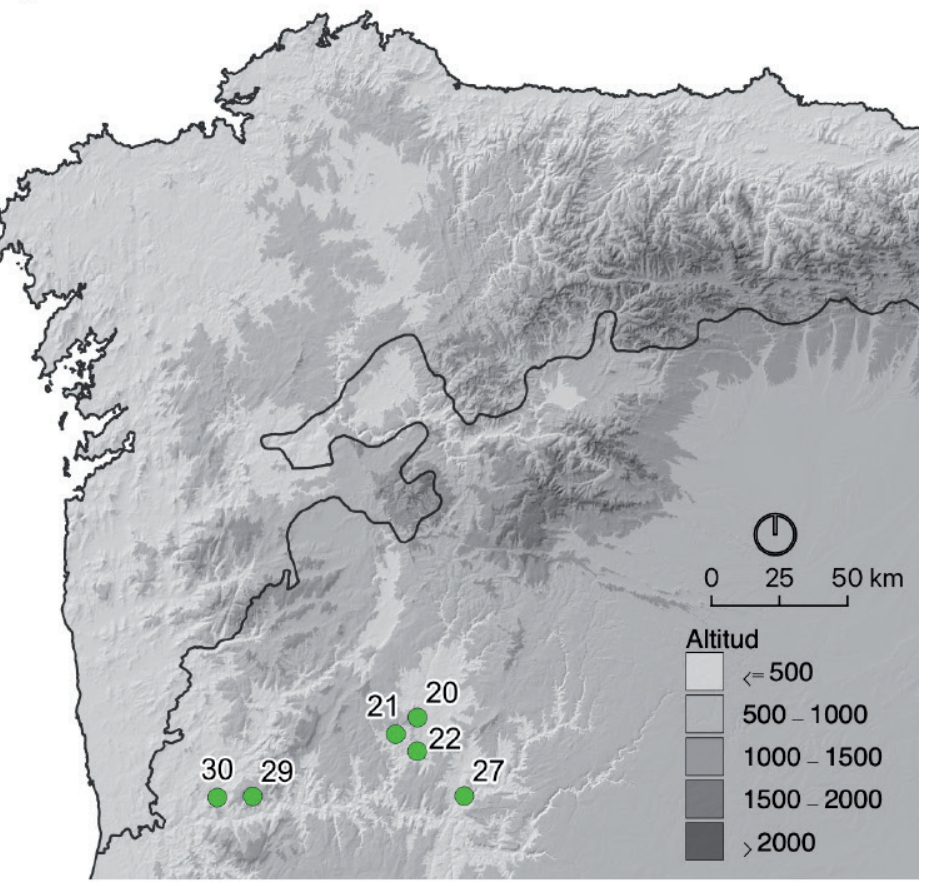

d) Período Romano

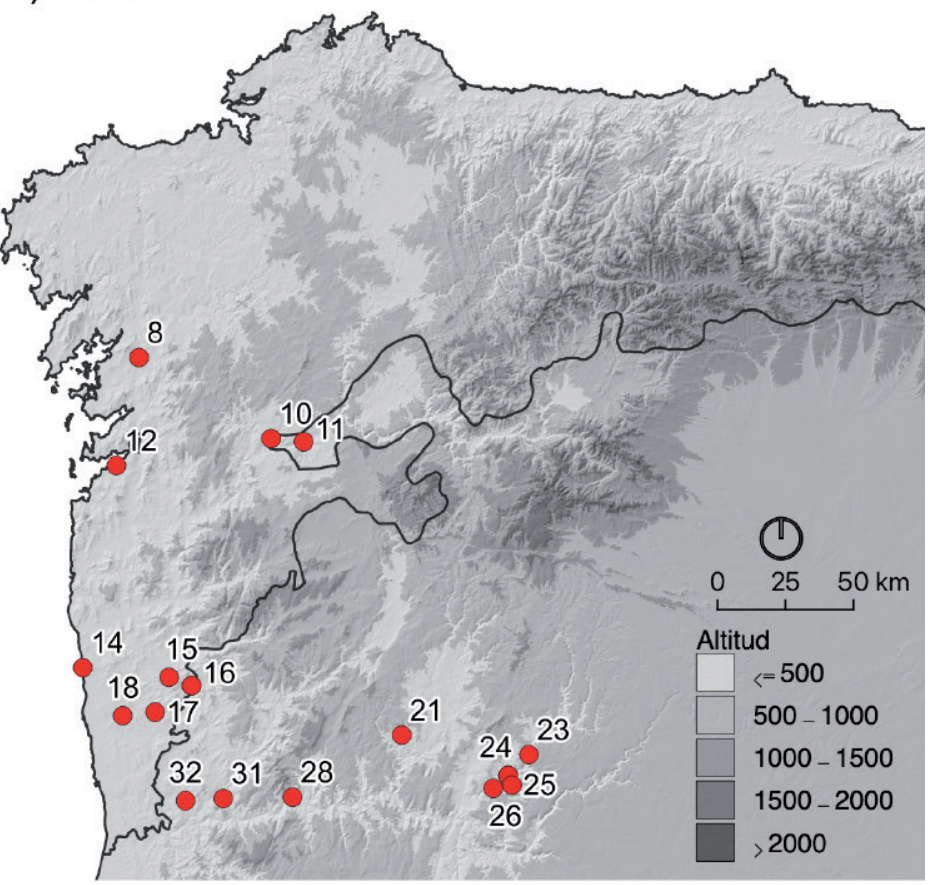

f) lagares rupestres

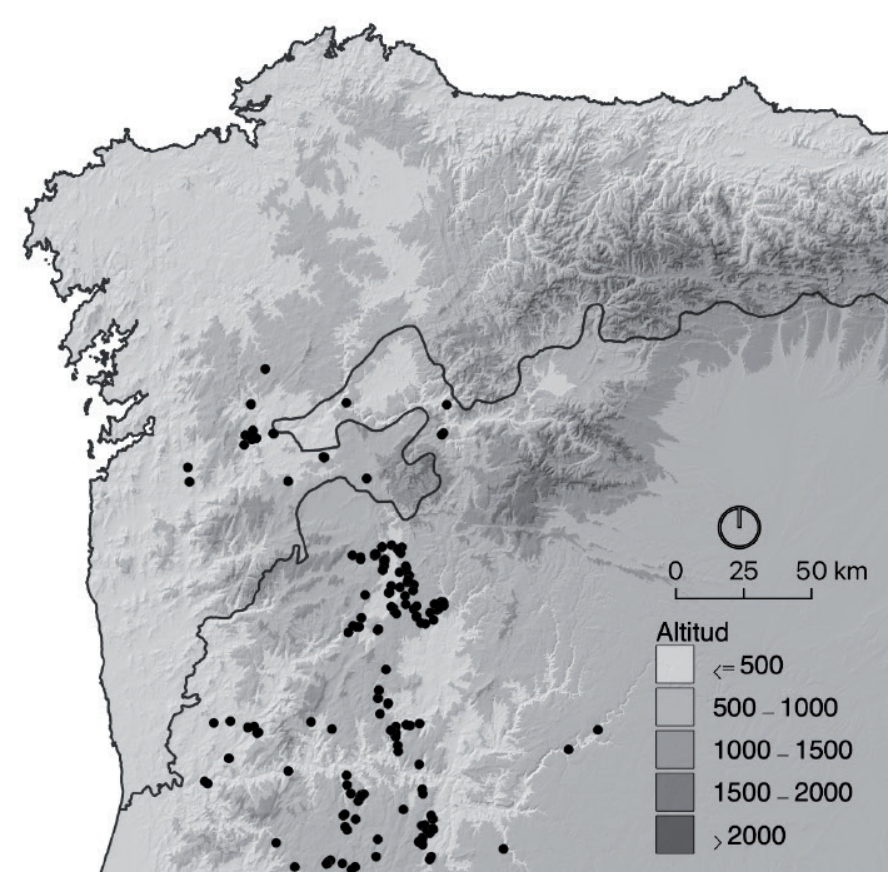

Figura 6. Evidencias arqueobotánicas de vid en a) depósitos naturales; y yacimientos arqueológicos del b) Neolítico a la Edad de Bronce, c) Edad del Hierro, d) Período romano, e) Alta Eda Media. f) lagares rupestres (bases de datos de la Dirección Xeral de Patrimonio de la Xunta de Galicia y el Endovélico de la Direção-Geral do Património Cultural de Portugal -Últimos accesos: 1 julio de 2017). Límite de las regiones biogeográficas atlántica -NO- y mediterránea -SE- a partir de Rivas Martínez (1987). 
SPAL 30.1

(2021)

\section{$165-195$}

ISSN: $1133-4525$ ISSN-e: 2255-3924
Pero, y como se ha señalado, deberá ser el estudio de su ADN el que deba asentar dicha hipótesis o, en su defecto, un mejor conocimiento arqueobotánico de los contextos productivos de la Edad del Hierro. Las evidencias, tanto en la importación de vajilla de mesa, de ánforas vinarias y de representaciones relacionadas con divinidades, muestran un abastecimiento desde las villae agropecuarias hacia las entidades poblacionales de fundación romana, como ciudades o campamentos militares. Además, la iconografía de este momento demuestra que las gestualidades y rituales en torno al consumo del vino se extienden más allá de las áreas productoras.

La parquedad de los datos arqueobotánicos y la problemática datación de los lagares condicionan el escaso conocimiento de la producción de vino en la Alta Edad Media. Este se plantea más desde una perspectiva documental que arqueológica, debido a una menor atención por la recuperación de evidencias vegetales en yacimientos históricos. Aun así, la distribución de los lagares rupestres, dentro de áreas de viñedo que más tarde son reconocidas en las fuentes escritas, expresa la existencia de comarcas productoras de vino con una continuidad desde época romana. La sistematización de más y mejores datos podrá resolver cuestiones en torno a la naturaleza socioeconómica de su explotación en el futuro.

\section{Agradecimientos}

Estimamos la generosidad demostrada por las personas que nos han facilitado información todavía sin publicar de sus trabajos. La intervención de O Freixo ha sido dirigida por Inés López-Dóriga, quien ha proporcionado las evidencias carpológicas a las que hacemos referencia en el texto. María Martín Seijo ha identificado los carbones de O Freixo y O Neixón Grande que incluimos y su fotografía. Andrés Currás Domínguez ha realizado el análisis de polen de A Fontela que mencionamos y Alessandra Pecci los contenidos de la anforeta de Rúa Ferreiría. Nuestro agradecimiento también a todas aquellas personas e instituciones que nos han permitido el uso de sus imágenes en las figuras: a Nuria Calo Ramos (fig.4), a Xulio Carballo Arceo (fig. 5a), al Museo Arqueolóxico Provincial de Ourense (fig. 3 y fig. 5c) y al Museo Municipal de Vigo Quiñones de León (fig. 5b).

Este trabajo es una consecuencia de la tesis doctoral de Andrés Teira Brión "Cambio e resiliencia na agricultura e xestión de recursos vexetais no NW da península ibérica (1000 a.n.e.-400 d.n.e.)". Josefa Rey Castiñeira es PDI del Grupo de Estudos para a Prehistoria do Noroeste-Arqueoloxía, Antigüidade e Territorio (GI-1534) del Departamento de Historia de la Universidade de Santiago de Compostela.

\section{BIBLIOGRAFÍA}

Aira Rodríguez, M. J. y Ramil Rego, P. (1995) “Datos paleobotánicos del Norte de Portugal (Baixo Minho) estudio polínico y paleocarpológico", Lagascalia, 18, pp. 25-38.

Almeida, C. A. B. d. (2006) "A Villa do Castellum da Fonte do Milho: uma antepassada das actuais quintas do Douro", Douro: Estudos \& Documentos, 21, pp. 209-228.

Almeida, C. A. B. d. (2011-2012) “Estruturas vinárias da Lusitânia e Gallaecia meridional”, en Noguera Celdrán, J. M. y Antolinos Marín, J. A. (eds.) Anales de Prehistoria y Arqueología, vol 2728. Murcia: Universidad de Murcia, pp. 487-494.

Almeida, C. A. F. d., Soeiro, T., Almeida, C. A. B. d. y Baptista, A. J. (1981) Escavaçoes arqueológicas em Santo Estevão da Facha. Ponte de Lima: Câmara Municipal de Ponte de Lima. 
SPAL 30.1

$(2021)$

\section{$165-195$}

ISSN: 1133-4525

ISSN-e: 2255-3924

Alonso Martínez, N. (2000) "Cultivos y producción agrícola en época ibérica", Saguntum: Papeles del Laboratorio de Arqueología de Valencia, Extra, 3, pp. 26-46.

Álvarez González, Y. (2019) El poblamiento castreño en la cuenca media del Miño: una visión diacrónica y territorial en la cuenca del Barbantiño. Madrid: Universidad Complutense.

Andrés, M. T., Benito, A., Pérez-Rivera, G., Ocete, R., López, M. A., Gaforio, L., Muñóz, G., Cabello, F., Martínez Zapater, J. M. y Arroyo García, R. A. (2012) "Genetic diversity of wild grapevine populations in Spain and their genetic relationships with cultivated grapevines", Molecular ecology, 21, pp. 800-816 http://doi.org/10.1111/j.1365-294X.2011.05395.x

Armada, X. L., García-Vuelta, Ó. y Seoane-Novo, C. (2018) “Cultural interaction in times of conflict: metals and ritual in the hillforts of north-western Iberia (2nd-1st centuries BC)", en Fontes, L., Cruz, G. y Alves, M. (eds.) Cultural Interactions and Changing Landscapes in Europe (2nd century BC / 2nd century AD). Braga: Unidade de Arqueologia da Universidade do Minho, pp. 56-71.

Arroyo García, R. A. y Revilla, E. (2013) "The Current Status of Wild Grapevine Populations (Vitis vinifera ssp sylvestris) in the Mediterranean Basin", en Poljuha, D. y Sladonja, B. (eds.) The Mediterranean Genetic Code - Grapevine and Olive. Rijeka: INTECH Open Access Publisher, pp. 51-72. http://doi.org/10.5772/52639

Arroyo-García, R., Ruíz-García, L., Bolling, L., Ocete, R., Lopez, M. A., Arnold, C., Ergul, A., Uzun, H. I., Cabello, F., Ibáñez, J., Aradhya, M. K., Atanassov, A., Atanassov, I., Balint, S., Cenis, J. L., Costantini, L., Goris-Lavets, S., Grando, M. S., Klein, B. Y., McGovern, P. E., Merdinoglu, D., Pejic, I., Pelsy, F., Primikirios, N., Risovannaya, V., Roubelakis-Angelakis, K. A., Snoussi, H., Sotiri, P., Tamhankar, S., This, P., Troshin, L., Malpica, M., Lefort, F. y Martínez-Zapater, J. M. (2006) “Multiple origins of cultivated grapevine (Vitis vinifera L. ssp. sativa) based on chloroplast DNA polymorphisms", Molecular ecology, 15, pp. 3707-3714.

Arruda, A. M. (2007) "Cerâmicas Gregas encontradas em Portugal”, en Raposo, L. (ed.) Vasos Gregos em Portugal - Aquém das colunas de Hércules. Lisboa: Instituto Português de Museus - Museu Nacional de Arqueologia, pp. 135-140.

Arruda, A. M. (2008) "Fenícios e púnicos em Portugal: problemas e perspectivas", Cuadernos de Arqueología Mediterránea, 18, pp. 13-24.

Bacilieri, R., Bouby, L., Figueiral, I., Schaal, C., Terral, J.-F., Breton, C., Picq, S., Weber, A. y Schlumbaum, A. (2017) "Potential of combining morphometry and ancient DNA information to investigate grapevine domestication", Vegetation History and Archaeobotany, 26, pp. 345-356. http://doi.org/10.1007/s00334-016-0597-4

Barbeito Pose, V. J., Fábregas Valcarce, R., Rodríguez Rellán, C., Martín Seijo, M., Cortegoso Comesaña, M. d. M., Fariña Costa, A., Paz Camaño, A., Lago Mallo, E., Lago Somoza, V. y Bustelo Abuín, J. (aceptado 7 noviembre 2019) “Investigando o Castro Grande de Neixón: as intervencións entre 2015-2018", Gallaecia, 38, e.p.

Barros, A. J. M. (2004) Porto: a construção de um espaço marítimo nos alvores dos tempos modernos. Porto: Universidade do Porto.

Bernal Casasola, D. (2015) "What contents do we characterise in Roman amphorae? Methodological and archaeological thoughts on a "trending topic"', en Oliveira, C., Morais, R. y Morillo Cerdán, Á. (eds.) ArchaeoAnalytics: Chromatography and DNA analysis in archaeology. Esposende: Municipio de Esposende, pp. 61-83.

Blanco-Rotea, R., Benavides García, R., Sanjurjo Sánchez, J. y Fernández Mosquera, D. (2009) "Evolución constructiva de Santa Eulalia de Bóveda (Lugo, Galicia)", Arqueología de la Arquitectura, 6, pp. 149-198. http://doi.org/10.3989/arqarqt.2009.09010

Boissinot, P. (2001) “Archéologie des vignobles antiques du sud de la Gaule”, Gallia, 58, pp. 45-68. Boso, S., Gago, P., Santiago, J. L., Teira-Brión, A., Martín-Seijo, M., Rey-Castiñeira, J., Ocete, R., Ocete, C. y Martínez, M. C. (2020) "Morphometric comparison of current, Roman-era and medieval Vitis seeds from the north-west of Spain ", Australian Journal of Grape and Wine Research, 26, pp. 300-309. https://doi.org/10.1111/ajgw.12439

Bouby, L., Figueiral, I., Bouchette, A., Rovira, N., Ivorra, S., Lacombe, T., Pastor, T., Picq, S., Marinval, P. y Terral, J.-F. (2013) “Bioarchaeological Insights into the Process of Domestication of Grape- 
SPAL 30.1

(2021)

\section{$165-195$}

ISSN: 1133-4525 ISSN-e: 2255-3924 vine (Vitis vinifera L.) during Roman Times in Southern France", PLOS ONE, 8: e63195. http:// doi.org/10.1371/journal.pone.0063195

Brown, A. G., Meadows, I., Turner, S. D. y Mattingly, D. J. (2001) "Roman vineyards in Britain: stratigraphic and palynological data from Wollaston in the Nene Valley, England", Antiquity, 75, pp. 745-757. http://doi.org/10.1017/S0003598X00089250

Brun, J.-P. (2004) Archéologie du vin et de l'huile dans l'Empire romain. París: Errance.

Brun, J.-P. (2011) "Los usos antiguos de los productos de la viña y el olivo y sus implicaciones arqueológicas", Anales de Prehistoria y Arqueología, 27-28, pp. 19-35.

Burillo Mozota, F. (2010) "La vid y el vino en el valle medio del Ebro durante la etapa prerromana”, en Mata Parreño, C., Pérez Jordá, G. y Vives-Ferrándiz Sánchez, J. (eds.) De la cuina a la taula. IV Reunió d'conomia en el primer mil.lenni aC, vol Sagvntum Extra 9. Valencia: Universitat de València, pp. 135-150.

Buxó, R. (2008) "The agricultural consequences of colonial contacts on the Iberian Peninsula in the first millennium BC", Vegetation History and Archaeobotany, 17, pp. 145-154. http://doi. org/10.1007/s00334-007-0133-7

Carballo Arceo, L. X. (1987): Castro da Forca. Campaña 1984. Arqueoloxía/Memorias, 8. Santiago de Compostela: Dirección Xeral de Patrimonio Artístico e Monumental, Xunta de Galicia.

Carreño Sánchez, E. (2005) "Las poblaciones de vid silvestre de la península ibérica y el origen de las variedades actuales", Revista Murciana de Antropología, 12, pp. 35-44.

Carrión, J. S. (2012), Paleoflora y paleovegetación de la peninsula Ibérica e Islas Baleares: Plioceno-Cuaternario. Edn. Murcia: Ministerio de Economía y Competitividad, Universidad de Murcia, Fundación Séneca.

Carrión Marco, Y., Peña-Chocarro, L., Sabato, D., Checa Gómez, E. y López-Romero González de la Aleja, E. (2015) "Las plantas enterradas: historia del uso y abandono del pozo-depósito de la Tabacalera de Gijón", en Fernández Ochoa, C., Orejas Saco del Valle, A., García Díaz, P. y Gil Sendino, F. (eds.) La Fábrica de Tabacos de Gijón. Arqueología e Historia de un espacio milenario. Gijón: Ayuntamiento de Gijón, pp. 210-225.

Carrocera Fernández, E. (2016) "Santa Eulalia de Bóveda (Lugo): ensayo sobre la cronología de las pinturas", Portvgalia, Nova Série, 37, pp. 163-188.

Cunha, J., Ibáñez, J., Teixeira-Santos, M., Brazão, J., Fevereiro, P, Martínez-Zapater, J. M. y Eiras-Dias, J. E. (2020): "Genetic Relationships Among Portuguese Cultivated and Wild Vitis vinifera L. Germplasm", Frontiers in Plant Science, 11. http://doi.org/10.3389/fpls.2020.00127

Cunha, J., Teixeira-Santos, M., Brazão, J., Fevereiro, P. y Eiras-Dias, J. E. (2013) "Portuguese Vitis vinifera L. germplasm: accessing its diversity and strategies for conservation", en Poljuha, D. y Sladonja, B. (eds.) The Mediterranean Genetic Code - Grapevine and Olive. Rijeka: INTECH Open Access Publisher, pp. 125-145.

Delibes de Castro, G. (1994) "Nuevos testimonios de joyería prerromana en territorio astur: a propósito de una arracada de oro, de apéndice en racimo, hallada en Castrillo de la Valduerna (León)", Brigecio, 4-5, pp. 61-74.

Dietler, M. (1998) "Consumption, agency, and cultural entanglement: theoretical implications of a Mediterranean colonial encounter", en Cusick, J. G. (ed.) Studies in culture contact: Interaction, culture change, and archaeology. Carbondale: Southern Illinois University Press, pp. 288-315.

Díez Platas, F. (2003) "Breviario de imágenes paganas: la iconografía de los dioses y el mito en la Galicia romana", Semata: Ciencias sociais e humanidades, 14, pp. 207-251.

Echevarría Sánchez, A. y Vera Rodríguez, J. C. (2015) "Los inicios de la viticultura en la península ibérica a partir de las huellas de cultivo", en Francia Verde, R. (ed.) Historia y arqueología en la cultura del vino. Logroño: Instituto de Estudios Riojanos, pp. 57-68.

Estrabón (1992): Geografia Libros III-IV (Meana, Mą J. y Piñeiro, F., trad.). Madrid: Editorial Gredos. Fernández Ochoa, C., Orejas Saco del Valle, A., García Díaz, P. y Gil Sendino, F. (eds.) (2015) La Fábrica de Tabacos de Gijón. Arqueología e historia de un espacio milenario. Gijón: Ayuntamiento de Gijón. 
SPAL 30.1

$(2021)$

\section{$165-195$}

ISSN: 1133-4525 ISSN-e: 2255-3924
Ferreira Priegue, E. M. (2005) "Galicia en la Marisma de Castilla: la dinámica de los intercambios mercantiles", en Arízaga Bolumburu, B. y Solórzano Telechea, J. Á. (eds.) El espacio urbano en la Europa medieval: Nájera. Encuentros Internacionales del Medievo. Logroño: Instituto de Estudios Riojanos, pp. 165-186.

Figueiral, I. (1995) "Evidence from charcoal analysis for environmental change during the interval late Bronze Age to Roman, at the archaeological site of Castro de Penices, NW Portugal", Vegetation History and Archaeobotany, 4, pp. 93-100.

Figueiral, I. y Sanches, M. d. J. (1998-1999) “A contribuição da antracologia no estudo dos recursos florestais de Trás-os-Montes e Alto Douro durante a Pré-história Recente", Portugalia, Nova Serie, 19-20, pp. 71-101.

Figueiral, I., Sanches, M. d. J. y Cardoso, J. L. (2017) “Crasto de Palheiros (Murça, NE Portugal, 3rd - 1st millennium BC): from archaeological remains to ordinary life", Estudos do Quaternàrio, 17, pp. $13-28$.

Fontes, L. y Magalhães, F. (2019) “Do presente ao passado: a intervenção arqueológica nos terrenos da Oficina de S. José, em Braga”, en Soares, M. I. d. P. (ed.) Da memória ao presente: a história da da Oficina de S. José de Braga. Braga: Oficina de S. José, pp. 309-320.

Francia Verde, R. (ed.) (2015) Historia y Arqueología en la cultura del vino. Logroño: Instituto de Estudios Riojanos.

Fuller, D. Q. y Stevens, C. J. (2019) "Between domestication and civilization: the role of agriculture and arboriculture in the emergence of the first urban societies", Vegetation History and Archaeobotany, 28, pp. 263-282. http://doi.org/10.1007/s00334-019-00727-4

García Antón, M., Gil Romera, G., Pagés, J. L. y Alonso Millán, A. (2006) "The Holocene pollen record in the Villaviciosa Estuary (Asturias, North Spain)", Palaeogeography, Palaeoclimatology, Palaeoecology, 237, pp. 280-292. http://dx.doi.org/10.1016/j.palaeo.2005.12.004

García Fernández, F. J. (2019) "Rumbo a poniente: el comercio de ánforas turdetanas en la costa atlántica de la península ibérica (siglos V-I a. C.)", Archivo Español de Arqueología, 92, pp. 119-153. http://doi.org/10.3989/aespa.092.019.007

García Fernández, F. J., Ferrer Albelda, E., Álvarez Mateos, P. y Durán Barrantes, M. M. (2016) “Análisis de residuos orgánicos y posibles contenidos en ánforas púnicas y turdetanas procedentes del valle del Guadalquivir", Sagvntvm: Papeles del Laboratorio de Arqueología de Valencia, 48, pp. 59-87. http://doi.org/10.7203/SAGVNTVM

García Fernández, F. J., Ferrer Albelda, E., Rodríguez-Corral, J., Sáez Romero, A. M. y Rey Castiñeira, J. (2020) "La presencia fenicio-púnica en los confines de Iberia", en Celestino Pérez, S. y Rodríguez González, E. (eds.) Un viaje entre el Oriente y el Occidente del Mediterráneo. Actas del IX Congreso Internacional de Estudios Fenicios y Púnicos, MYTRA, 5, vol. IV. Mérida: Instituto de Arqueología, pp. 1513-1530.

García y Bellido, A. (1969) “Esculturas romanas de Galicia”, Cuadernos de Estudios Gallegos, 24, pp. 27-34.

García-Amorena, I., Morla, C., Rubiales, J. M. y Gómez Manzaneque, F. (2008) “Taxonomic composition of the Holocene forests of the northern coast of Spain, as determined from their macroremains", The Holocene, 18, pp. 819-829.

González Soutelo, S., Gutiérrez Garcia-M., A. y Royo Plumed, H. (2014) “El mármol de O Incio: proyecto de caracterización, estudio de la explotación y uso de un marmor local en la Galicia romana", en Álvarez Martínez, J. M., Nogales Basarrate, T. y Rodà de Llanza, I. (eds.) Actas XVIII Congreso Internacional de Arqueología Clásica. Centro y periferia en el Mundo Clásico. Mérida: Museo Nacional de Arte Romano, pp. 323-326.

González Soutelo, S., Vidal Álvarez, S., Gutiérrez Garcia-M., A. y Royo Plumed, H. (2016) “La placa de Amiadoso (Allariz, Ourense): Nuevos datos sobre el uso del mármol local en el noroeste de Hispania a partir de un estudio interdisciplinar", Espacio Tiempo y Forma Serie I, Prehistoria y Arqueología, 9, pp. 99-121. http://doi.org/10.5944/etfi.9.2016.17540

Hidalgo Cuñarro, J. M. (1978) "Importantes hallazgos en el castro "A Cidade" de Caneiro (Fozara, Ponteareas)", El Museo de Pontevedra, 32, pp. 59-63. 
SPAL 30.1

$(2021)$

\section{$165-195$}

ISSN: 1133-4525

ISSN-e: 2255-3924

Iriarte Chiapusso, M. J. y Hernández Beloqui, B. (2009) "Evolución del bosque durante el pleistoceno superior y holoceno en Bizkaia: un estado de la cuestión provisional", Kobie (Serie Paleoantropología), 28, pp. 9-24.

Iriarte-Chiapusso, M. J., Salinas López, J. A., Pérez Izquierdo, M. A., Ocete Rubio, M. E. y Ocete Rubio, R. (2013) "La vid silvestre, un taxón amenazado en diversos ecosistemas ibéricos", en Iriarte Goñi, I., Aragón Ruano, Á. y Silva Pando, F. J. (eds.) Actas del IV Encuentro de Historia Forestal: gestión forestal y sostenibilidad: experiencias históricas. Vitoria: Sociedad Española de Ciencias Forestales, pp. 143-148.

Jesus, A., Tereso, J. P. y Gaspar, R. (2020) "Interpretative trajectories towards the understanding of negative features using Terraço das Laranjeiras Bronze Age site as a case study", Journal of Archaeological Science: Reports, 30, p. 102222. https://doi.org/10.1016/j.jasrep.2020.102222

Leite, M. I. A. A., Tereso, J. P. y Sanches, M. d. J. (2018) "Cultivos da Idade do Ferro no Crasto de Palheiros: novos dados carpológicos da Plataforma Inferior Leste", Cadernos do Grupo de Estudos em Evolução Humana, 7, pp. 40-68.

Lewit, T. (2020) " 'terris, vineis, olivetis...': wine and oil production after the villas", European Journal of Post-Classical Archaeologies, 10, pp. 193-217.

Lillo Carpio, P. A. (1991-1992) "Los exvotos de Bronce del santuario de La Luz y su contexto arqueológico (1990-1992)", Anales de Prehistoria y Arqueología, 7-8, pp. 107-142.

Limier, B., Ivorra, S., Bouby, L., Figueiral, I., Chabal, L., Cabanis, M., Ater, M., Lacombe, T., Ros, J., Brémond, L. y Terral, J.-F. (2018) “Documenting the history of the grapevine and viticulture: A quantitative eco-anatomical perspective applied to modern and archaeological charcoal", Journal of Archaeological Science, 100, pp. 45-61. https://doi.org/10.1016/j.jas.2018.10.001

Llana Rodríguez, J. C., García Valdeiras, M. y Lamas, R. (2011) "Lagares rupestres ao ar libre na provincia de Ourense", Boletín Auriense, 41-42, pp. 457-486.

López, D., Jornet, R., Morer, J. y Asensio, D. (2014) "La vitivinicultura preromana al Penedès: indicadors arqueològics a Font de la Canya (Avinyonet del Penedès, Alt Penedès, Barcelona)", en Sáncho, D. (ed.) El món de la viticultura, els vins, caves i aiguardents al Penedès històric i al Camp de Tarragona, Actes del V Seminari d'Història del Penedès. Vilafranca del Penedès: Institut d'Estudis Penedesencs, pp. 31-52.

López Merino, L., López Sáez, J. A., Abel Schaad, D., Sánchez Palencia, F. J. y Reher Díez, G. (2008) "Dinámica antrópica en El Bierzo (León) desde época romana: estudio palinológico de Castro Ventosa", Polen, 18, pp. 25-36.

López Sabatel, J. A. (2007) "Cultivos agrícolas en la Ribeira Sacra durante los siglos XIV y XV", Espacio, Tiempo y Forma, 20, pp. 183-198.

López-Dóriga, I. (2020): “Estudios arqueobotánicos en Tongobriga: muestreo y resultados preliminares", en Tongobriga: coletânea de estudos comemorativos de 40 anos de investigação, vol 6. Património a Norte. Porto: Direção Regional de Cultura do Norte - Ministério de Cultura, pp. 81-97.

Martín i Oliveras, A., Martín-Arroyo Sánchez, D. J. y Revilla Calvo, V. (2017) "The wine economy in Roman Hispania. Archaeological data and modellization", en Remesal Rodríguez, J. (ed.) Economía romana. Nuevas perspectivas/The roman economy. New perspectives. Barcelona: Universitat de Barcelona, pp. 189-237.

Mata Parreño, C., Badal García, E., Bonet Rosado, H., Collado Mataix, E., Fabado Alós, F. J., Fuentes Albero, M., Izquierdo Peraile, I., Moreno Martín, A., Ntinou, M., Quixal Santos, D., Ripollès Alegre, P. P. y Soria Combadiera, L. (2010) “Comida para la eternidad", en Mata Parreño, C., Pérez Jordá, G. y Vives-Ferrándiz Sánchez, J. (eds.) De la cuina a la taula. IV reunió d'economia en el primer Millenni aC, Sagvntum Extra, 9. Valencia: Universitat de València, pp. 277-286.

Mighall, T. M., Martínez Cortizas, A., Biester, H. y Turner, S. E. (2006) "Proxy climate and vegetation changes during the last five millennia in NW Iberia: Pollen and non-pollen palynomorph data from two ombrotrophic peat bogs in the North Western Iberian Peninsula", Quaternary non-pollen palynomorphs, 141, pp. 203-223. http://dx.doi.org/10.1016/j.revpalbo.2006.03.013

Montenegro Rúa, E. J. (2016): Santa Eulalia de Bóveda. Estudio histórico-arqueológico y propuesta interpretativa del monumento y su entorno. Madrid: Universidad Autónoma de Madrid. 
SPAL 30.1

$(2021)$

\section{$165-195$}

ISSN: 1133-4525 ISSN-e: 2255-3924
Naveiro López, J. L. (1991) El comercio antiguo en el NW peninsular. A Coruña: Museo Arqueolóxico e Histórico, D.L.

Noguera Celdrán, J. M. y Antolinos Marín, J. A. (eds.) (2011-2012) De vino et oleo Hispaniae. Áreas de producción y procesos tecnológicos del vino y el aceite en la Hispania romana. Coloquio Internacional, Anales de Prehistoria y Arqueología, vol 27-28. Murcia: Universidad de Murcia.

Oliveira, C., Morais, R. y Araújo, A. (2015) "Application of gas cromatography coupled with mass spectrometry to the analysis of ceramic containers of roman period evidence from the peninsular Northwest", en Oliveira, C., Morais, R. y Morillo Cerdán, Á. (eds.) ArchaeoAnalytics: Chromatography and DNA analysis in archaeology. Esposende: Municipio de Esposende, pp. 193-212.

Orrù, M., Grillo, O., Lovicu, G., Venora, G. y Bacchetta, G. (2013) "Morphological characterisation of Vitis vinifera L. seeds by image analysis and comparison with archaeological remains", Vegetation History and Archaeobotany, 22, pp. 231-242.

Pagnoux, C., Bouby, L., Ivorra, S., Petit, C., Valamoti, S.-M., Pastor, T., Picq, S. y Terral, J.-F. (2015) “Inferring the agrobiodiversity of Vitis vinifera L. (grapevine) in ancient Greece by comparative shape analysis of archaeological and modern seeds", Vegetation History and Archaeobotany, 24, pp. 75-84.

Parcero Oubiña, C., García Vuelta, Ó. y Armada, X. L. (2009) "Contextos y tecnologías de la orfebrería castreña: En torno a una nueva arracada de Punta dos Prados (Espasante, Ortigueira, A Coruña)", Complutum, 20, pp. 83-108. https://dx.doi.org/10.5209/CMPL

Pecci, A., Barba, L. y Ortiz, A. (2017) "Chemical Residues as Anthropic Activity Markers. Ethnoarchaeology, Experimental Archaeology and Archaeology of Food Production and Consumption", Environmental Archaeology, 22, pp. 343-353. http://doi.org/10.1080/14614103.2017.1359354

Peña Cervantes, Y. (2005-2006) "Producción de vino y aceite en los asentamientos rurales de Hispania durante la Antigüedad Tardía (s. IV-VII d.C.)", Cuadernos de Prehistoria y Arqueología de la Universidad Autónoma de Madrid, 31-32, pp. 103-116.

Peña Cervantes, Y. (2010) Torcularia. La producción de vino y aceite en Hispania, Documenta, 14. Tarragona: Institut Català d'Arqueologia Clàssica.

Peña Cervantes, Y. (2019) "Los lagares rupestres de la península ibérica: sistemas de estrujado y problemática cronológica", Revista ArkeoGazte, 9, pp. 83-99.

Peña-Chocarro, L., Orejas Saco del Valle, A., Carrión Marco, Y., Pérez-Díaz, S., López-Sáez, J. A. y Fernández Ochoa, C. (2015) "Late Antique Environment and Economy in the North of the Iberian Peninsula: The Site of La Tabacalera (Asturias, Spain)", Late Antique Archaeology, 11, pp. 155-171. https://doi.org/10.1163/22134522-12340058

Peña-Chocarro, L., Pérez Jordà, G., Alonso, N., Antolín, F., Teira-Brión, A., Tereso, J. P., Montes Moya, E. M. y López Reyes, D. (2019) "Roman and Medieval crops of the Iberian Peninsula: a first synthesis of seeds and fruits from archaeological sites", Quaternary International, 499, pp. 49-66. https://doi.org/10.1016/j.quaint.2017.09.037

Peña-Chocarro, L. y Zapata, L. (2005) "Trade and new plant foods in the western Atlantic coast: The Roman port of Irun (Basque Country)", en Urteaga Artigas, M. M. y Noain Maura, M. J. (eds.) Mar Exterior. El Occidente Atlántico en época romana. Actas del Congreso Internacional. Pisa 6-9 noviembre 2003. Roma: Escuela Española de Historia y Arqueología-CSIC, pp. 159-167.

Perea, A., García Vuelta, Ó. y Fernández Freire, C. (2010) El proyecto AU: estudio arqueométrico de la producción de oro en la península ibérica. Madrid: Consejo Superior de Investigaciones Científicas.

Pereira Sieso, J. (1988) "La cerámica ibérica de la cuenca del Guadalquivir. I Propuesta de clasificación", Trabajos de Prehistoria, 45, pp. 143-173.

Pérez Jordá, G. (2015) "El cultivo de la vid y la producción de vino en la península ibérica durante el I milenio ane", en Francia Verde, R. (ed.) Historia y arqueología en la cultura del vino. Logroño: Instituto de Estudios Riojanos, pp. 47-55.

Pérez Outeiriño, B. (1982) De ourivesaría castrexa, Boletin Auriense, vol 1. Ourense: Museo Provincial de Ourense. 
SPAL 30.1

$(2021)$

\section{$165-195$}

ISSN: 1133-4525 ISSN-e: 2255-3924
Pérez-Jordá, G., Peña-Chocarro, L., García Fernández, M. y Vera Rodríguez, J. C. (2017) "The beginnings of fruit tree cultivation in the Iberian Peninsula: plant remains from the city of Huelva (southern Spain)", Vegetation History and Archaeobotany, 26, pp. 1-12. http://doi. org/10.1007/s00334-017-0610-6

Pérez-Jordà, G., Peña-Chocarro, L. y Pardo-Gordó, S. (2021) “Fruits arriving to the west. Introduction of cultivated fruits in the Iberian Peninsula", Journal of Archaeological Science: Reports, 35, p. 102683. https://doi.org/10.1016/j.jasrep.2020.102683

Pinto da Silva, A. R. (1988) A paleoetnobotânica na arqueologia portuguesa. Resultados desde 1931 a 1987. Actas do Encontro "Paleoecologia e Arqueologia". Vila Nova de Famalicão: Câmara Municipal de Vila Nova de Famalicão.

Portela Silva, E. (1976) La región del Obispado de Tuy en los siglos XII a XV: una sociedad en la expansión y en la crisis. Santiago de Compostela: El Eco Franciscano.

Portela Silva, E. y Pallares Méndez, M. C. (1998) "La villa, por dentro: Testimonios galaicos de los siglos X y XI", Studia Historica: Historia Medieval, 16, pp. 14-43.

Queiroga, F. (1992) War and Castros. New approaches to the northwestern Portuguese Iron Age. Oxford: University of Oxford.

Queiroz, P. F. y Mateus, J. E. (2007) Acerca das Grainhas de Uva da Idade do Ferro de Castro Marim, Traballhos do CIPA, vol 105. Lisboa: Centro de Investigação en Paleoecologia Humana e Arqueociências.

Ramil Rego, P. y Aira Rodríguez, M. J. (1993) “A palaeocarpological study of Neolithic and Bronze Age levels of the Buraco da Pala rock-shelter (Bragança, Portugal)", Vegetation History and Archaeobotany, 2, pp. 163-172.

Ramil Rego, P., Muñoz Sobrino, C., Gómez-Orellana, L., Rodríguez Guitián, M. A. y Ferreiro da Costa, J. (2012) "Configuración y transformacion del paisaje del NW ibérico durante el final de los tiempos glaciares, el Holoceno y el Antropoceno", Recursos Rurais, 6, pp. 19-62.

Ramos-Madrigal, J., Runge, A. K. W., Bouby, L., Lacombe, T., Samaniego Castruita, J. A., Adam-Blondon, A.-F., Figueiral, I., Hallavant, C., Martínez-Zapater, J. M., Schaal, C., Töpfer, R., Petersen, B., Sicheritz-Pontén, T., This, P., Bacilieri, R., Gilbert, M. T. P. y Wales, N. (2019) "Palaeogenomic insights into the origins of French grapevine diversity", Nature Plants, 5, pp. 595-603. http:// doi.org/10.1038/s41477-019-0437-5

Rey Castiñeira, J. (2019): "Cultura castrexa. Territorios, tiempos y aculturaciones", en Ferrer Albelda, E. (ed.) La ruta de las Estrímnides. Navegación y conocimiento del litoral atlántico de iberia en la Antigüedad, Monografías de Gahia, 4. Alcalá de Henares, Sevilla: Universidad de Alcalá, Universidad de Sevilla, pp. 423-447.

Riaz, S., De Lorenzis, G., Velasco, D., Koehmstedt, A., Maghradze, D., Bobokashvili, Z., Musayev, M., Zdunic, G., Laucou, V., Andrew Walker, M., Failla, O., Preece, J. E., Aradhya, M. y Arroyo-Garcia, R. (2018) "Genetic diversity analysis of cultivated and wild grapevine (Vitis vinifera L.) accessions around the Mediterranean basin and Central Asia", BMC Plant Biology, 18, p. 137 https://doi.org/10.1186/s12870-018-1351-0 (consultado 8-06-2020).

Rivas Martínez, S. (1987) Memoria del mapa de series de vegetación de España 1:400.000. Madrid: Ministerio de Agricultura, Pesca y Alimentación.

Rodrigo-Estevan, M. L. (2016): "Maneras de beber, maneras de vivir. El consumo de vino en época medieval", en Fournier, D. y Ávila, R. (eds.) Modos de beber, Colección Estudios del Hombre, 31. Serie antropología de la Alimentación. Guadalajara: Universidad de Guadalajara.

Rodríguez Muñiz, V., Reboreda Carreira, A. y Nieto Muñiz, E. B. (2016) Arqueoloxía do viño: os lagares rupestres da comarca de Monterrei. Ourense: Deputación Provincial de Ourense.

Sá Coixão, A. N. y Silvino, T. (2006) "O Sítio Arqueológico do Rumansil I (Murça do Douro, Vila Nova de Foz Côa - Portugal)", Côavisão Cultura e Ciência, 8, pp. 118-137.

Sáez Romero, A. M. (2010) "Comercio, procesado y consumo. Análisis evolutivo de algunas familias cerámicas gadiritas de época púnica y tardopúnica", Sagvntvm, Extra, 9, pp. 303-312.

Sáez Romero, A. M. (2018) “Apuntes sobre las dinámicas comerciales de Gadir entre los siglos VI y III a.C. ", Gerión, 36, pp. 11-40. 
SPAL 30.1

$(2021)$

\section{$165-195$}

ISSN: 1133-4525 ISSN-e: 2255-3924
Sáez Romero, A. M., García Fernández, F. J., Ferrer Albelda, E., Rodríguez Corral, J. y Rey Castiñeira, J. (2019) “Proyecto Estrimnides: Resultados Preliminares", en Ferrer Albelda, E. (ed.) La ruta de las Estrímnides. Navegación y conocimiento del litoral atlántico de Iberia en la Antigüedad, Monografías de Gahia, 4. Alcalá de Henares, Sevilla: Universidad de Alcalá, Universidad de Sevilla, pp. 567-650.

Sanches, M. d. J. (2016) "Animal bones, seeds and fruits recovered from Crasto de Palheiros. A contribution to the study of diet and commensality in the recent Pre-History and Iron Age of Northern Portugal", en Vilaça, R. y Serra, M. (eds.) Matar a fame, alimentar a alma, criar sociabilidades. Alimentação e comensalidade nas sociedades pré e proto-históricas. Coimbra: Instituto de Arqueologia, Centro de Estudos Pré-Históricos da Beira Alta, Palimpsesto, Estudo e Preservação do Património Cultural Lda., pp. 85-125.

Sánchez Pardo, J. C. (2008) Territorio y poblamiento en Galicia entre la Antigüedad y la Plena Edad Media. Santiago de Compostela: Universidade de Santiago de Compostela.

Sánchez Pardo, J. C. (2010): "Poblamiento rural tardorromano y altomedieval en Galicia (s. V-X). Una revisión arqueológica", Archeologia Medievale, 37, pp. 285-306.

Sánchez-Goñi, M. F. (1996): "Vegetation and sea level changes during the Holocene in the estuary of the Bidasoa (Southern part of the bay of Biscay)", Quaternaire, 7, pp. 207-219.

Seabra, L., Santos, F., Vaz, F. C., Leite, J. y Tereso, J. P. (2020) "Crops behind closed walls: Fortified storage at Castelinho in the Late Iron Age of NW Iberia", Journal of Archaeological Science: Reports, 30, p. 102200. https://doi.org/10.1016/j.jasrep.2020.102200

Seabra, L. C. N., Tereso, J. P., Bettencourt, A. M. S. y Dinis, A. P. (2018a) "Diversidad de cultivos y estructuras de almacenaje en el poblado de Crastoeiro (Noroeste de la península ibérica): nuevos enfoques", Trabajos de Prehistoria, 75, pp. 361-378. http://doi.org/10.3989/ tp.2018.12221

Seabra, L. C. N., Tereso, J. P., Bettencourt, A. M. S. y Dinis, A. P. (2018b) "Evidências arqueobotânicas e de armazenagem no povoado da Idade do Ferro e na Romanização do Crastoeiro (Mondim de Basto, Norte de Portugal)", Cadernos do GEEvH, 7, pp. 1-26.

Silva, A. C. F. (1986): A cultura castreja no Norte de Portugal. Paços de Ferreira: Museu Arqueológico da Citânia de Sanfins.

Solórzano Telechea, J. Á. (2018) "Integración económica, compentencia y jerarquización de los puertos atlánticos del norte de España (siglos XIII-XV)", Anuario de Estudios Medievales, 48, pp. 213-242.

Suárez Piñeiro, A. M. (2005) "El vino en la antigüedad romana y su introducción en el Noroeste peninsular", en García Tato, I. y Suárez Piñeiro, A. M. (eds.) Actas de La cultura del vino: Primer Congreso Peninsular. O Barco de Valdeorras 10-12 mayo 2002. Santiago de Compostela: Instituto de Estudios Gallegos “Padre Sarmiento", pp. 43-66.

Teira Brión, A. (2010) "Wild fruits, domesticated fruits. Archaeobotanical remains from the Roman saltworks at O Areal, Vigo (Galicia, Spain)", en Delhon, C., Théry-Parisot, I. y Tiébault, S. (eds.) Des hommes et des plantes. Exploitation du milieu et gestión des resources végétales de la Préhistoire à nous jours, XXXe rencontres internationales d'archéologie et d'histoire d'Antibes. Antibes: Éditions APDCA, pp. 199-207.

Teira Brión, A. (2015) "Cultivos e froiteiras na Idade Media en Galicia. O conxunto carpolóxico da escavación do Banco de España (Santiago de Compostela)", Gallaecia, 34, pp. 209-226.

Teira Brión, A. (2019) Cambio e resiliencia na agricultura e xestión de recursos vexetais no NW da península ibérica (1000 a.n.e.-400 d.n.e.). Tesis Doctoral. Universidade de Santiago de Compostela. Accesible en: http://hdl.handle.net/10347/20497

Tereso, J. P. (2012) Environmental change, agricultural development and social trends in NW Iberia from the Late Prehistory to the Late Antiquity. Tesis Doctoral. Universidade do Porto. Accesible en: https://repositorio-aberto.up.pt/ bitstream/10216/65095/2/24032.pdf

Tereso, J. P., Bettencourt, A. M. d. S., Ramil-Rego, P., Teira-Brión, A., López-Dóriga, I., Lima, A. y Almeida, R. (2016) "Agriculture in NW Iberia during the Bronze Age: A review of archaeobotanical data", Journal of Archaeological Science: Reports, 10, pp. 44-58. http://dx.doi.org/10.1016/j. jasrep.2016.07.011 


\section{SPAL 30.1 $(2021)$}

\section{5-195}

ISSN: $1133-4525$ ISSN-e: 2255-3924
Tereso, J. P., Ramil-Rego, P. y Almeida-da-Silva, R. (2013a) "Roman agriculture in the conventus Bracaraugustanus (NW Iberia)", Journal of Archaeological Science, 40, pp. 2848-2858.

Tereso, J. P., Ramil-Rego, P., Pires De Carvalho, T., Almeida-da-Silva, R. y Vaz, F. C. (2013b) “Crops and fodder: evidence for storage and processing activities in a functional area at the Roman settlement of Monte Mozinho (northern Portugal)", Vegetation History and Archaeobotany, 22, pp. 479-492.

Tereso, J. P., Vaz, F. C., Pereira, S., Mateos, R. y Pereira, J. A. (2018) “Recursos vegetais num sítio rural: dados arqueobotânicos no sítio romano da Foz da Ribeira do Poio (Mogadouro, Nordeste de Portugal)", en Roque, A. C., Melo, C. J. d., Amorim, I., Freitas, J. G. d. y Torrão, M. M. (eds.) Alterações ambientais em perspetiva Histórica, Encontro da Rede Portuguesa de História do Ambiente, vol II. Lisboa: CITCEM - Centro de Investigação Transdisciplinar Cultura, Espaço e Memória, pp. 149-179.

Terral, J.-F., Tabard, E., Bouby, L., Ivorra, S., Pastor, T., Figueiral, I., Picq, S., Chevance, J.-B., Jung, C. y Fabre, L. (2010) “Evolution and history of grapevine (Vitis vinifera) under domestication: new morphometric perspectives to understand seed domestication syndrome and reveal origins of ancient European cultivars", Annals of Botany, 105, pp. 443-455.

Tornqvist, T. E., Janssen, C. R. y Pérez Alberti, A. (1989) "Degradación antropogénica de la vegetación en el noroeste de Galicia durante los últimos 2500 años", Cuadernos de Estudios Gallegos, 38, pp. 175-198.

Ucchesu, M., Orrù, M., Grillo, O., Venora, G., Usai, A., Serreli, P. F. y Bacchetta, G. (2015) “Earliest evidence of a primitive cultivar of Vitis vinifera L. during the Bronze Age in Sardinia (Italy)", Vegetation History and Archaeobotany, 24, pp. 587-600. http://doi.org/10.1007/s00334-014-0512-9

Ucchesu, M., Orrù, M., Grillo, O., Venora, G., Paglietti, G., Ardu, A. y Bacchetta, G. (2016) “Predictive Method for Correct Identification of Archaeological Charred Grape Seeds: Support for Advances in Knowledge of Grape Domestication Process", PLOS ONE, 11, e0149814. http://doi. org/10.1371/journal.pone.0149814

Vaz, F. C., Braga, C., Tereso, J. P., Oliveira, C., Carretero, L. G., Detry, C., Marcos, B., Fontes, L. y Martins, M. (2020) "Food for the dead, fuel for the pyre: symbolism and function of plant remains in provincial Roman cremation rituals in the necropolis of Bracara Augusta (NW Iberia)", Quaternary International. https://doi.org/10.1016/j.quaint.2020.08.054 (consultado 8-06-2020).

Vaz, F. C., Tereso, J. P., Lemos, P. P. y Abranches, P. B. (2016a) "Estudo arqueobotânico do Castro de Cidadelhe (Mesão Frio): resultados preliminares", Estudos do Quaternário / Quaternary Studies, 15, pp. 59-69.

Vaz, F. C., Tereso, J. P., Martín-Seijo, M., Pereira, S. S., Gaspar, R., Seabra, L. y Sastre-Blanco, J. (2017) "Iron Age ovens and hearths from the hilltop of Quinta de Crestelos, Sabor Valley (NE Portugal): An archaeobotanical approach on typology, functionality and firewood use", Quaternary International, 458, pp. 75-93. http://dx.doi.org/10.1016/j.quaint.2017.02.028

Vaz, F. C., Tereso, J. P., Pereira, J. A. y Pereira, S. S. (2016b) "O potencial interpretativo de contextos secundários e terciários: o caso do estudo arqueobotânico de Chã (Alfândega da Fé)", Cadernos do Grupo de Estudos em Evolução Humana, 5, pp. 7-28.

Vidal Caeiro, L. (2003) “Santa Eulalia de Bóveda: Análisis de los ladrillos”, Gallaecia, 22, pp. 225-252. Vidal Caeiro, L. (2006) “Arqueología de Santa Eulalia de Bóveda”, en III Premio de investigación Manuel Vázquez Seijas. Lugo: Deputación Provincial de Lugo, Museo Provincial de Lugo, pp. 11-122.

Vigil-Escalera Guirado, A. (2018) "Relectura arqueológica del pozo-cisterna de la fortaleza de Gijón (Asturias, Norte de España): la civitas Gegionem durante el primer siglo del Reino de Asturias (720-840 AD)", Munibe Antropologia-Arkeologia, 69, pp. 265-281. https://doi. org/10.21630/maa.2018.69.20

VV.AA. (2012) Gallaecia Petrea. Santiago de Compostela: Xunta de Galicia.

Wales, N., Ramos Madrigal, J., Cappellini, E., Carmona Baez, A., Samaniego Castruita, J. A., Romero-Navarro, J. A., Carøe, C., Ávila-Arcos, M. C., Peñaloza, F., Moreno-Mayar, J. V., Gasparyan, B., Zardaryan, D., Bagoyan, T., Smith, A., Pinhasi, R., Bosi, G., Fiorentino, G., Grasso, A. M., Celant, A., Bar-Oz, G., Tepper, Y., Hall, A., Scalabrin, S., Miculan, M., Morgante, M., Di Gaspero, G. y Gil- 
SPAL 30.1 (2021)

\section{$165-195$}

ISSN: $1133-4525$

ISSN-e: 2255-3924 bert, M. T. P. (2016) "The limits and potential of paleogenomic techniques for reconstructing grapevine domestication", Journal of Archaeological Science, 72, pp. 57-70. http://dx.doi. org/10.1016/j.jas.2016.05.014

Zohary, D., Hopf, M. y Weiss, E. (2012) Domestication of Plants in the Old World: The origin and spread of domesticated plants in Southwest Asia, Europe, and the Mediterranean Basin. 4a edn. Oxford: Oxford University Press.

\section{Contribución Autores}

- Andrés Teira Brión: Concepción y diseño. Análisis e interpretación de los datos. Redacción del borrador. Recogida de datos. Diseño gráfico.

- Josefa Rey Castiñeira: redacción del borrador y revisión crítica del artículo. 